إمكانية الوصول للمطارات الرئيسة في العراق باستخدام الـ GIS

\author{
د. دممد هاشم ذنون الحيالي

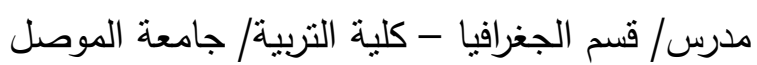

مستخلص البحث

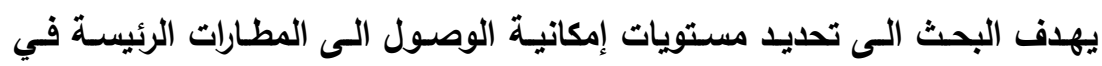

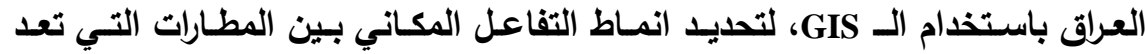

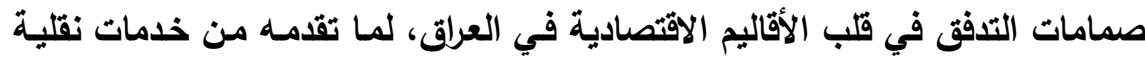

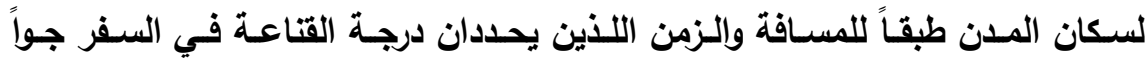

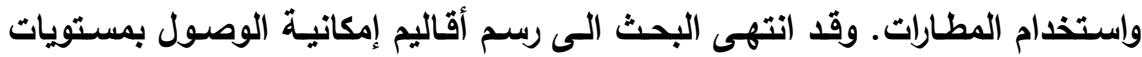
هرمية متعددة عالية، متوسطة، قليلة، تحدد قرار السكان باستخدام المطارات . بالتالي التهاتي

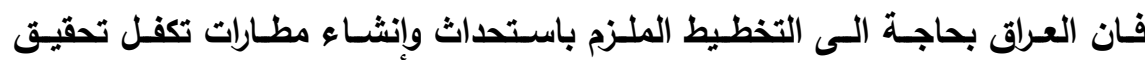

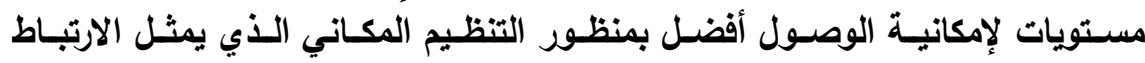
العضوي بين الجغرافيا والتنمية.

المقدمة

تعـد المطـارات بمثابـة البنيـة التحتيـة لأنظمـة النقل الجـوي في بيئات

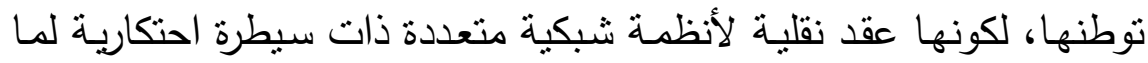

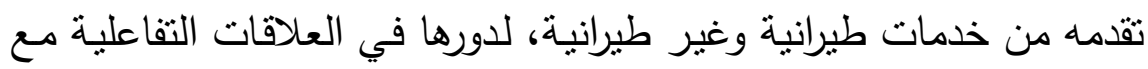

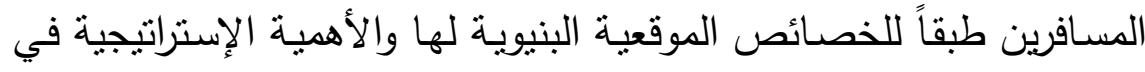

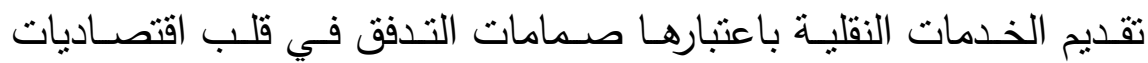
الأقاليم بنطاقات خدمتها النقلية لسكان مدن ظهيرها المباشر وغير المباشر

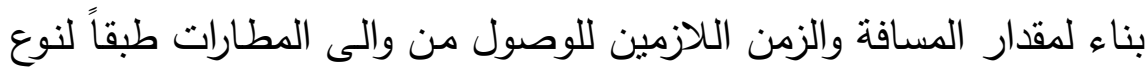
شبكات وسائط النقل المعتمدة في الحركة التي تحدد مدى إمكانية الوصول

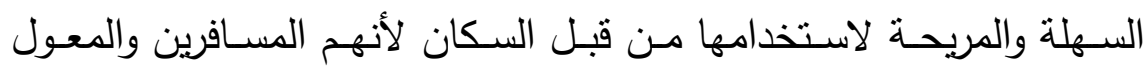


عليهم بكافة أوجه الأنشطة الاقتصادية المتعددة بالتالي تحديد درجة القناعة بالسفر جواً. من هنا بدأ التفكير بدراسة مشكلة البحث التي تتمثل بان هنالك تباين في

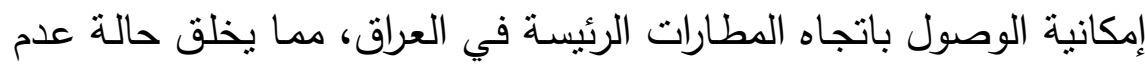

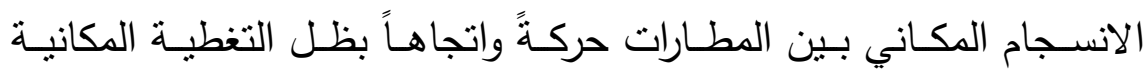
للمطارات في أقاليم مكانية متعددة.

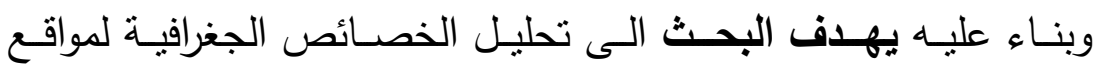
ومواضع المطارات، وتحديد المستويات المكانية طبقاً للوزن النسبي المرجح

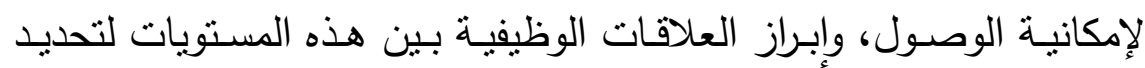
أقاليم إمكانية الوصول إلى المطارات في العراق.

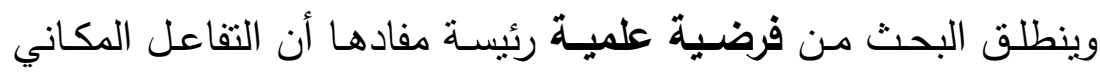

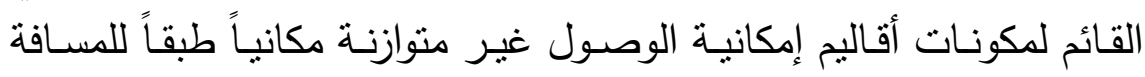

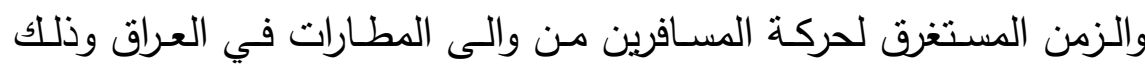

$$
\text { لوجود المشكلات الآتية: }
$$

عدم التوازن المكاني لمواقع المطارات وقرب وبعد المدن عنها. ارتفاع نسبة سكان المدن المخدومة من قبل مطار واحد.

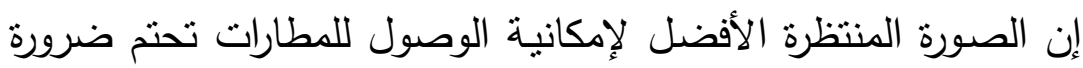
التخطيط إن إنور ولأجل الوصول إلى هدف البحث والتحقق من فرضيته فقد قسم البحث إلى ثلاثنة محاور تمنلت بـ: دراسـة الخصائص الجغرافية الموقعية والمكانية للمطارات، تقييم إمكانية الوصول للمطارات بنطاقات مكانية متباينة المسافة والزمن المستغرق، تحديد الأنماط الوظيفية لأقاليم إمكانية الوصول للمطارات

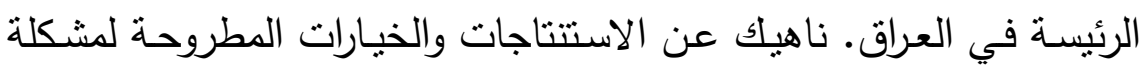


تأسيساً على ما تقدم بنطوي البحث تحت لواء جغرافية النقل التي تتعدد

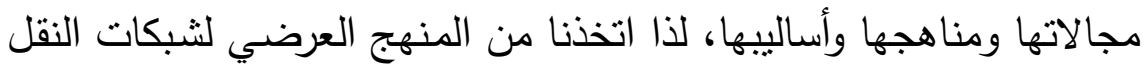
ركيزة أساسية في تقييم إمكانية الوصول للمطارات انطلاقاً من تحديد المراكز

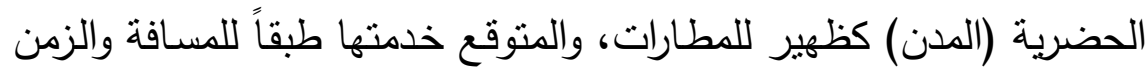
كمتغيرات تسـهم في تحديد قرار الإفراد باستخدام المطارات، بالتالي تكوين

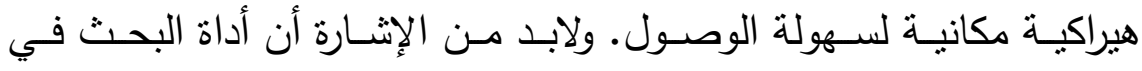
التحليل والتقييم وتحديد أنماط إمكانية الوصول تمتلت بالإمكانيات التطبيقية لـ GIS، وخاصـة في تحليل الاقتراب Proximity Analysis من خلال أداة

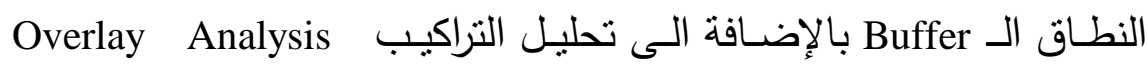
باستخدام برنامج الـ r Arc GIS 9, التي أفصحت عن نتائج نرقى بالمستوى المعرفي والمنهجي لجغرافيا النقل التطبيقية. ولعل من الموضوعية الإشارة الى أن البحث استتد على البيانات الوثائقية

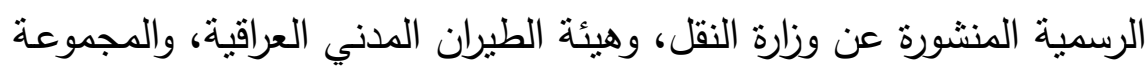

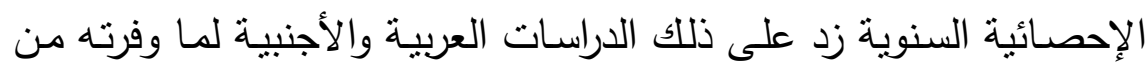
بيانات شكلت المدخلات الرئيسة للبحث الذي تجسدت مخرجاته داته بان العراق

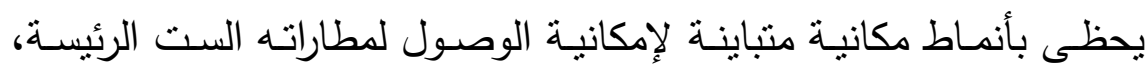

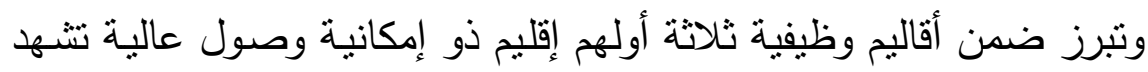

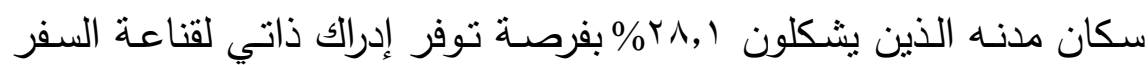

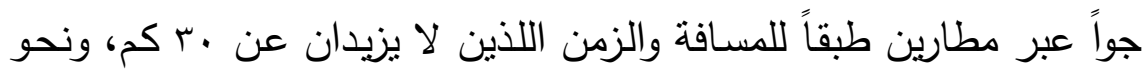

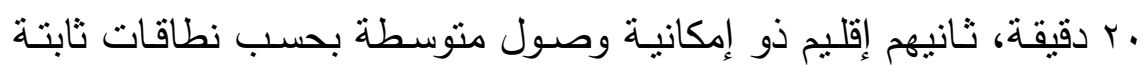
تحيط بالمطارات بمسافة .0 كم حيث قرار سكان المدن التي شكلت أهميته

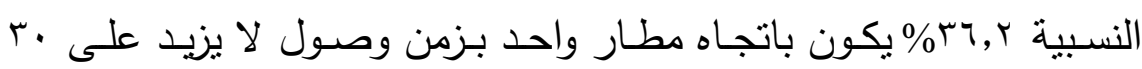

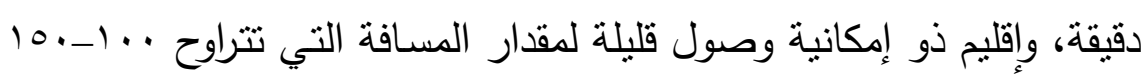
كم، وزمن بتراوح بين •ج-، و دقيقة المستغرق للوصول لمطار واحد من قبل 


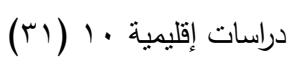

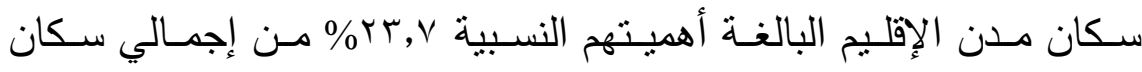

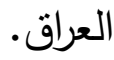

وتركزت الخيارات المطروحة بضرورة التخطيط والالتزام بالتنفيذ لإنشاء

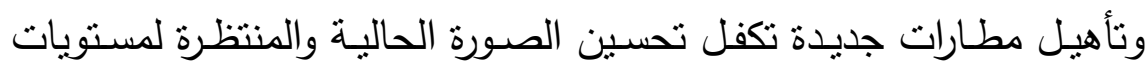

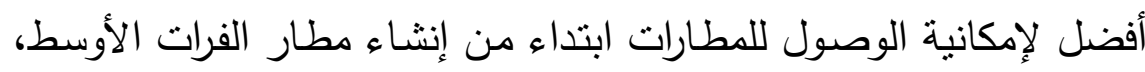

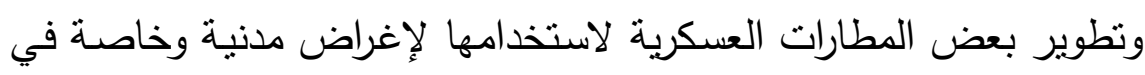

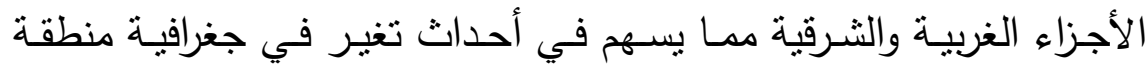
الدراسة في ظل إرادة وطنية تتموية.

\section{1. الخصائص الجغرافية للمطارات الرئيسة في العرلق}

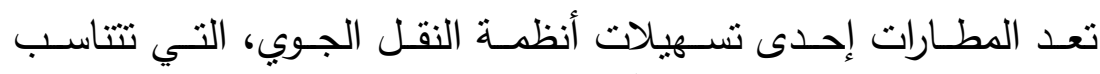

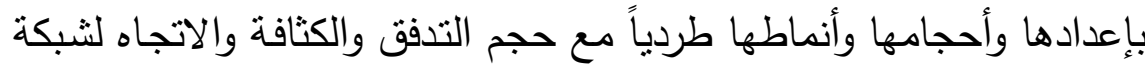

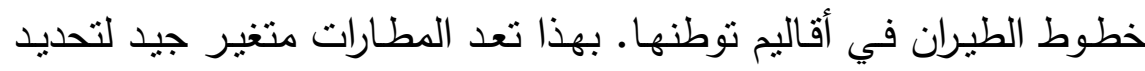

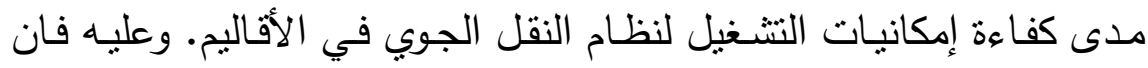

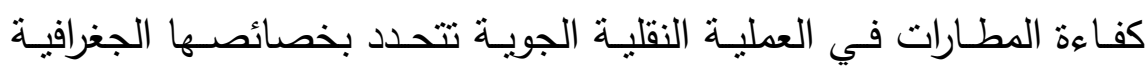

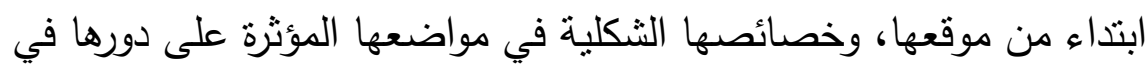

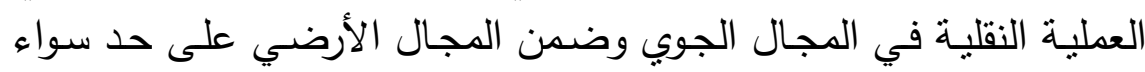

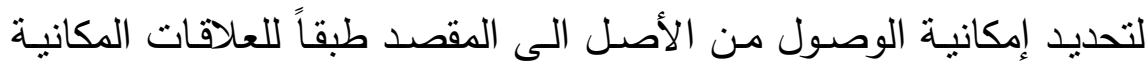
الترابطية بين كافة أوجه نسهيلات النقل الجوي والأنظمة النقلية الأخرى.

$$
\text { 1-1. التوزيع الجغرافي لمطارات العرلق }
$$

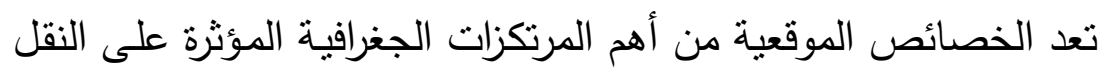

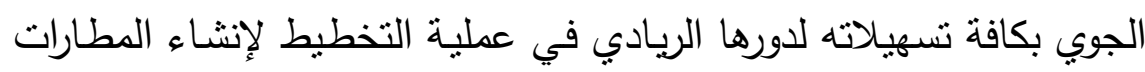

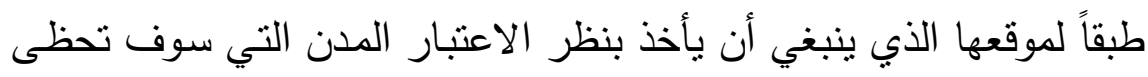

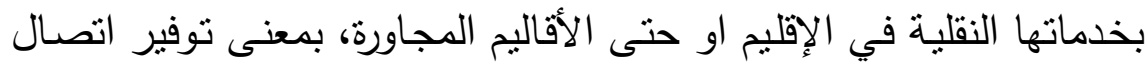

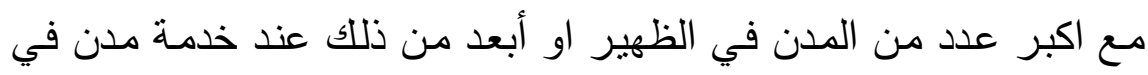




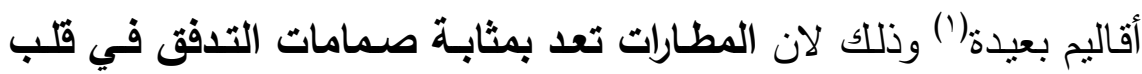

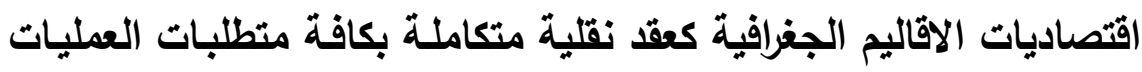
النقلية المتعددة لموقعها بالنسبة لنطاقات خدمتها النقلية للركاب والبضائع

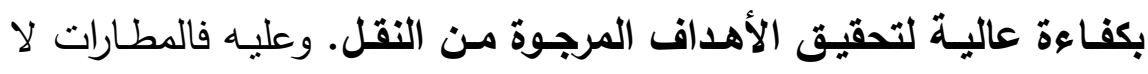
تعتبر عقد بدايـة او نهايـة مسـارات وسـائط النقل الجوي فقط إنمـا لمسـارات وسائط الأنظمة النقلية الأخرى طبقاً لموقعها في نطاقات خدماتها المكانية

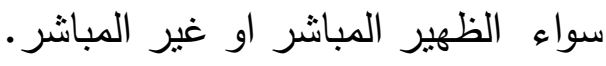

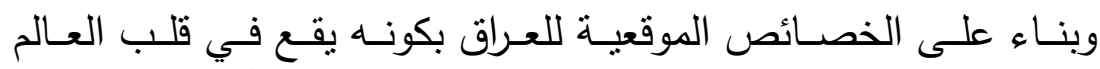

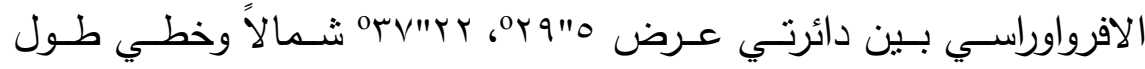

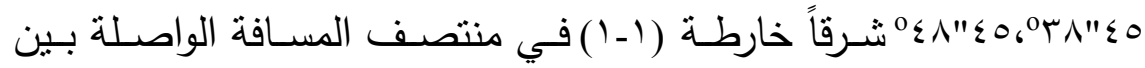

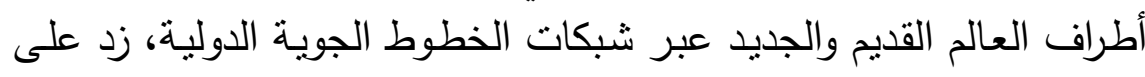

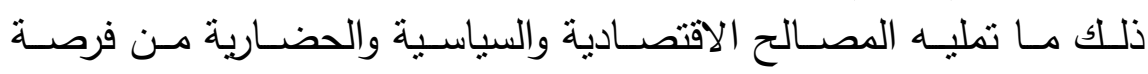

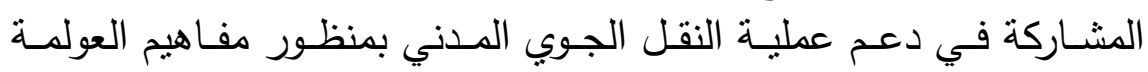

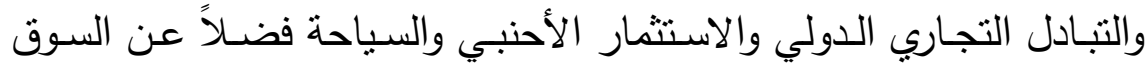

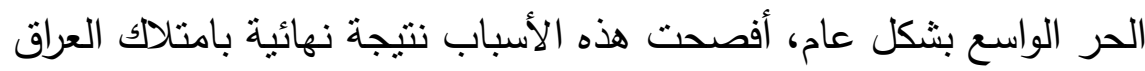

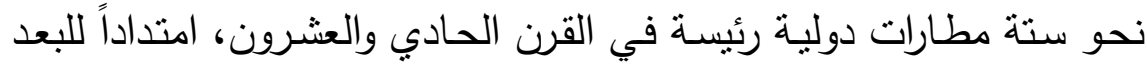
التاريخي الذي حظي بها العراق في مجال صناعة النقل الجوي التي ترجع

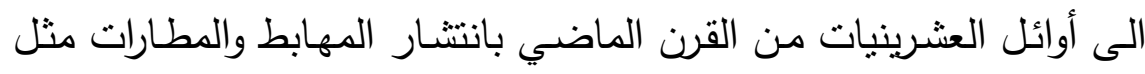

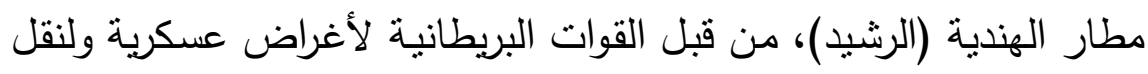

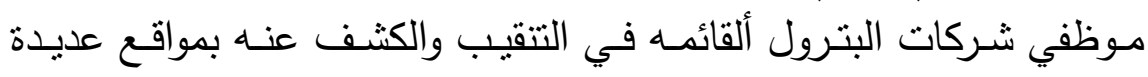

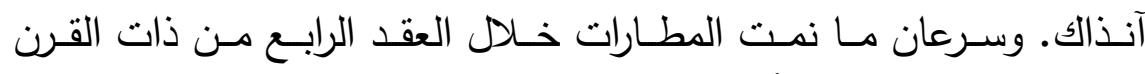
الماضي (العشرين) بعد أنشاء مطارات من الدرجة الثانية في بغداد والبصرة

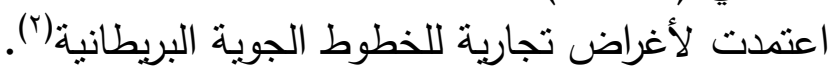
خارطة (1 - الموقع الجغرافي للعراق في شبكات خطوط الطيران الرئيسة

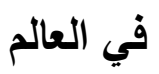


دراسات إقليمية . 1 ( (T)

[

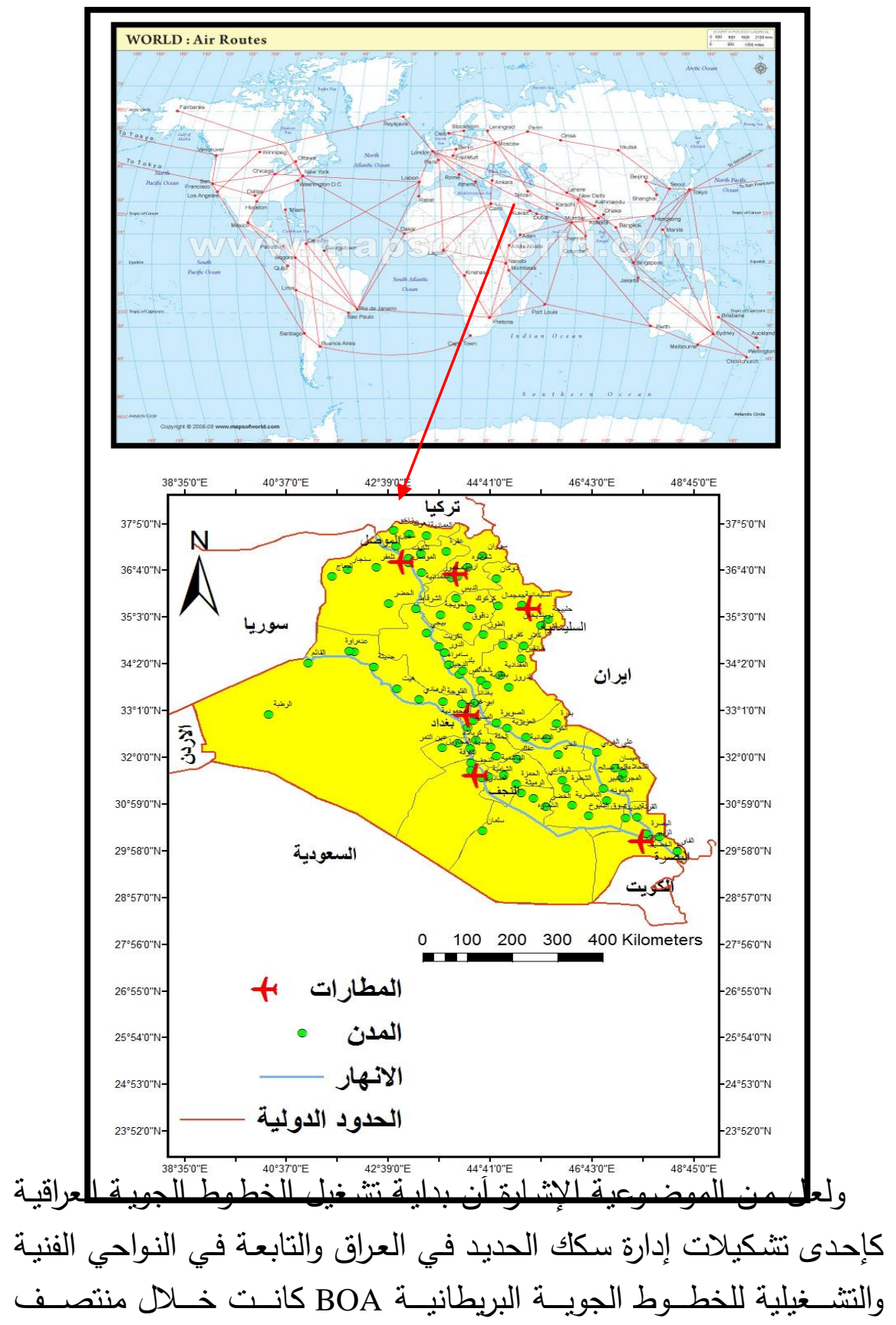


الأربعينيات، وباستمرار نمو النقل الجوي خاصة في سبعينيات وثمانينيات

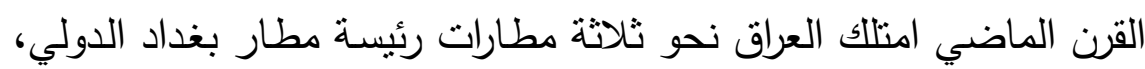

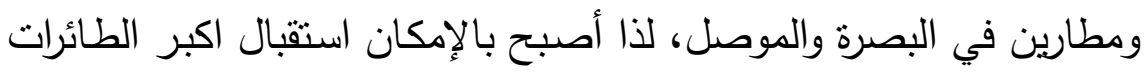

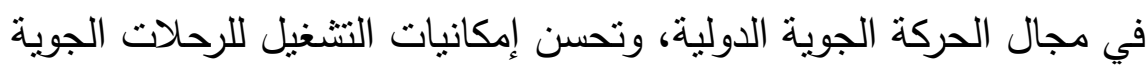

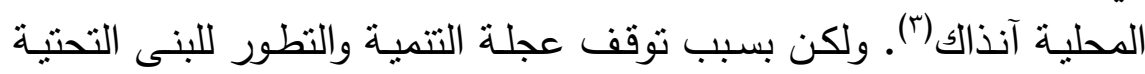

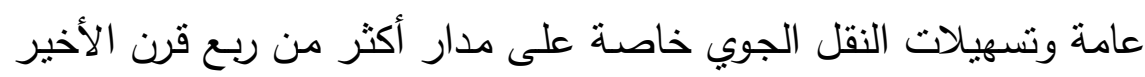

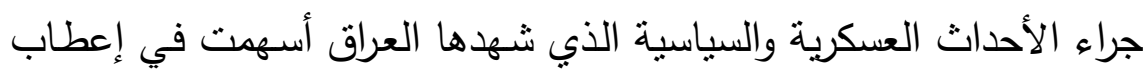

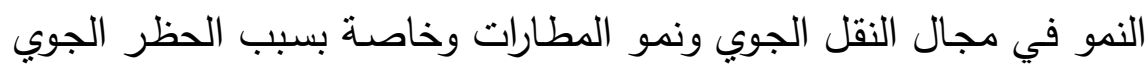

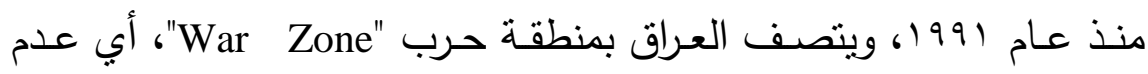

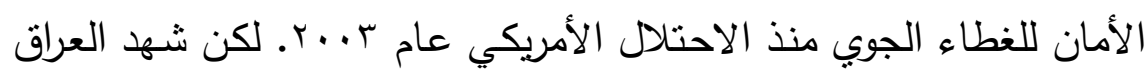

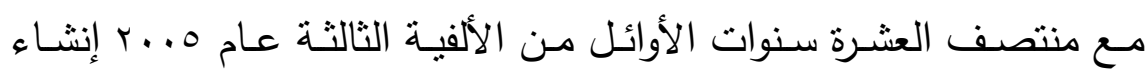

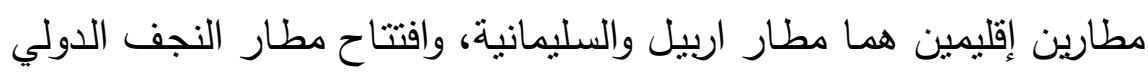

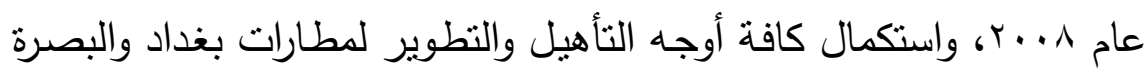

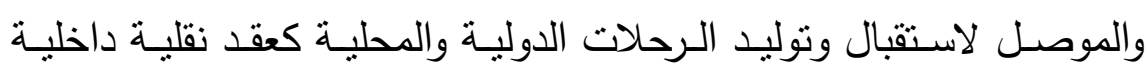
وبوابات نفوذ للاولة متباينة في توزيعها الجغرافي ضمن ثلائلة لالثة محاور مكانية

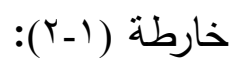

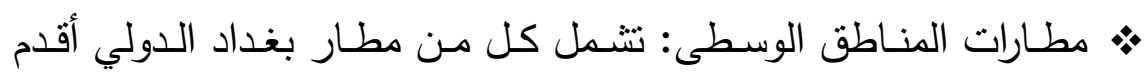

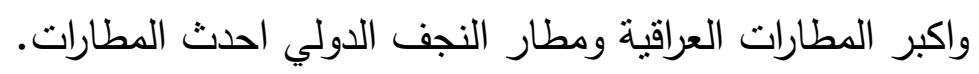

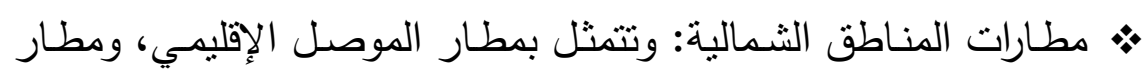
اربيل الدولي في أقصى الأجزاء الثمالية، ومطار السليمانية في الأجزاء النياء الثمالية الثرقية.

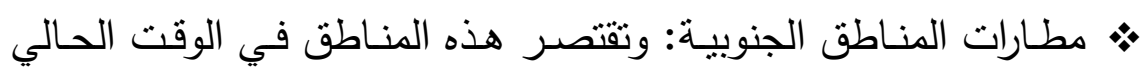

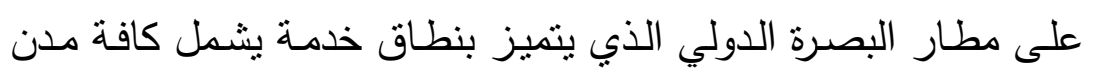
محافظة البصرة ومحافظات ميسان وذي قار . لإنيز 


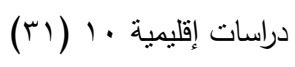

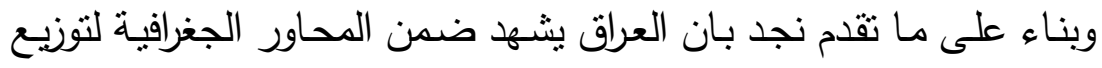
المطارات بأنه يمتلك فقط ستة مطارات رئيسة قائمة في مجال النتشيل لنظام النقل الجوي التي تكفل ربط أجزائهه مـع بعضهـا البعض عبر شبكة الخطوط المحلية، وبذات الوقت تربط العراق دولياً بمطارات دول العالم.

خارطة (1- ا التوزيع المكاني للمطارات الرئيسة في العراق

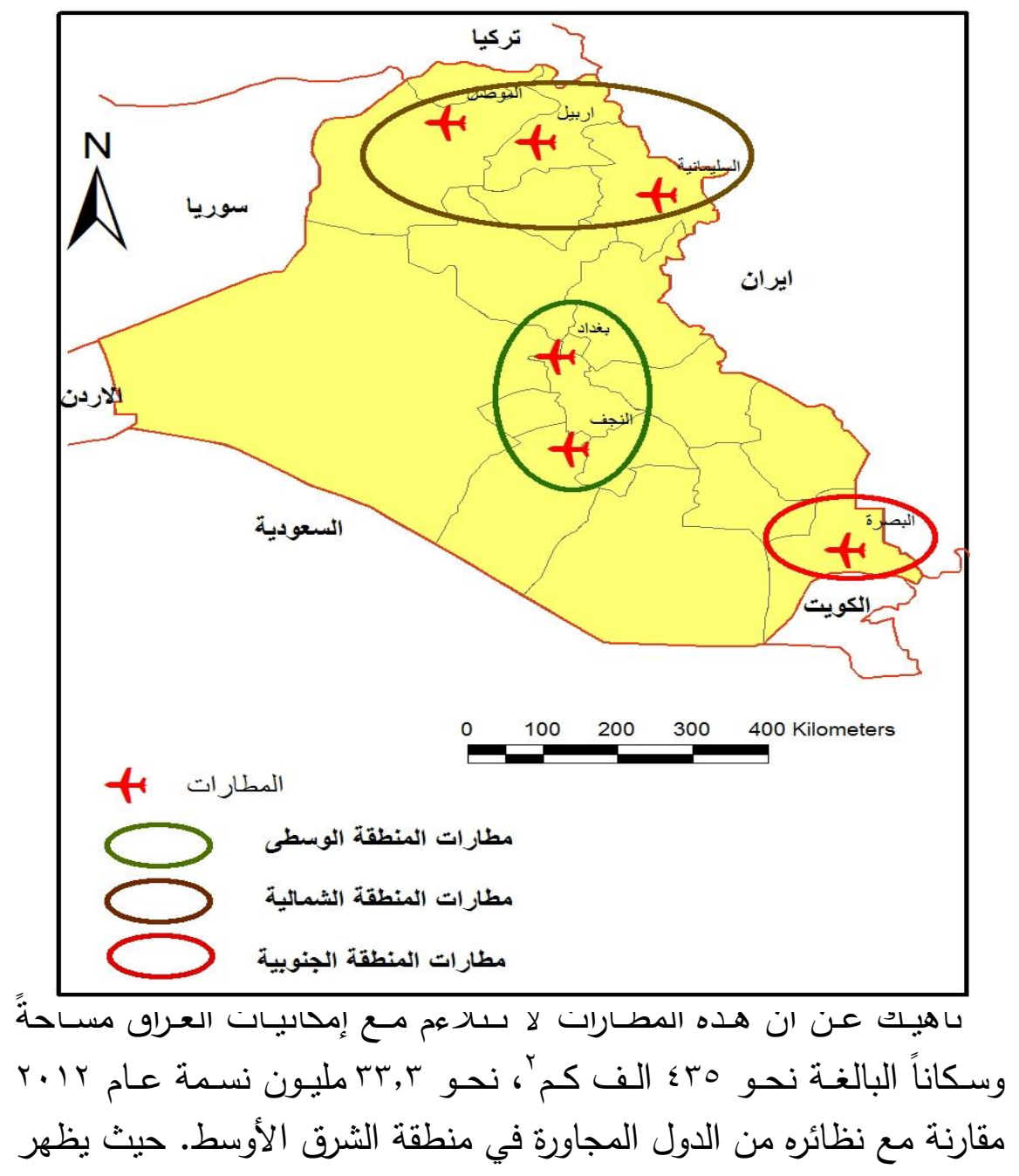


مـن الجدول (1 ـ () إن الأهميـة النسبية للعـراق مـن حيـث المسـاحة وحجم

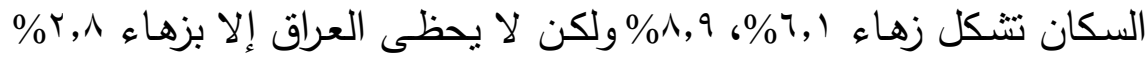

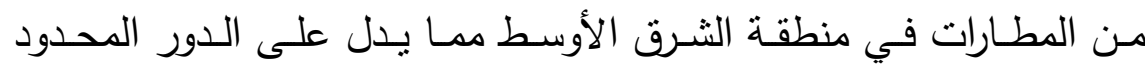

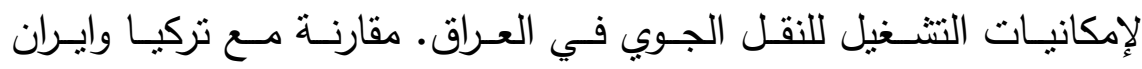

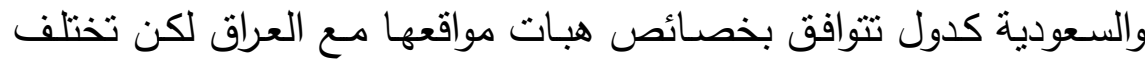
عنه بإمكانيات ريع موضعها، ويتضـح من الأهمية النسبية لأعداد مطاراتها

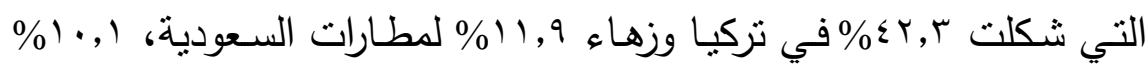
في إيران من إجمالي دول منطقة الثرق الأوسط عام r باء ب شكل (1- (1). جدول (1- إ): الأهمية النسبية للمطارات والمتغيرات المكانية في العراق

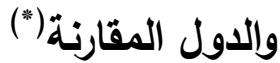

\begin{tabular}{|c|c|c|c|c|c|c|}
\hline \multicolumn{3}{|c|}{ الأهمية النسبية \% } & \multirow{2}{*}{ 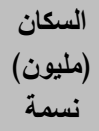 } & \multirow{2}{*}{ (ألف)كمبح } & \multirow{2}{*}{ المطارات } & \multirow{2}{*}{ 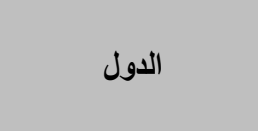 } \\
\hline ال السكان & المساحة & المطارات & & & & \\
\hline$\wedge, q$ & 7,1 & $r, \wedge$ & 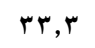 & or & 7 & العراق \\
\hline$v, 0$ & $r q, q$ & 11,9 & $r \wedge, 1$ & Y10. & rq & السعودية \\
\hline 19,9 & rY, q & $1 \cdot, 1$ & $v \leq, \Lambda$ & $17 \leqslant 1$ & rr & إيران \\
\hline \multirow[t]{2}{*}{$r, r$} & $1 \cdot, 9$ & $\varepsilon r, r$ & va,v & v^r & 9. & تركيا \\
\hline & & & rVד, I & 1990 & ris & منطقة الثرق الأوسط \\
\hline
\end{tabular}

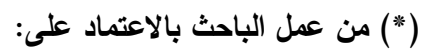

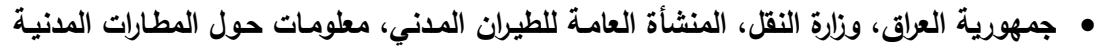
http;//www.geca.gov.iq /

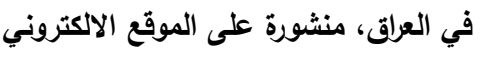

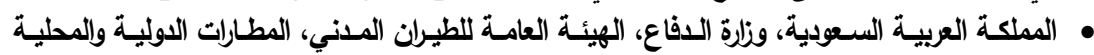
http;//www.gaca.gov.sa/ بالملكة، بيانات ومطظومات منشورة على موقع الالكتروني للوزارة • معلومات من الموسوعة الحرة (الويكيبيديا) لتركيا وايران من شبكة المعلومات الدولية 


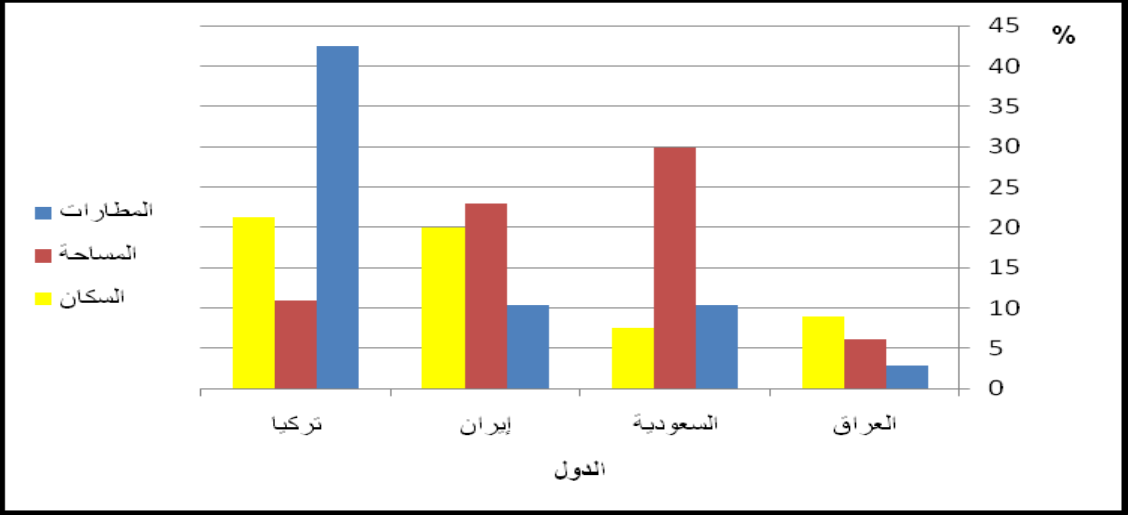

شكل (1-1): الأهمية النسبية للمطارات والمتغيرات المكانية للعرلق ودول المقارنة

\section{1-r. الخصائص المكانية للمطارات الرئيسة في العرلق}

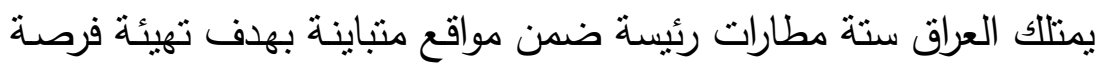

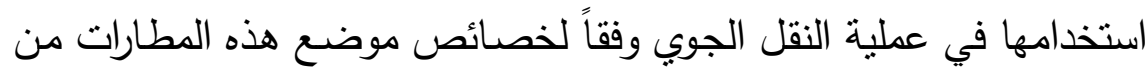

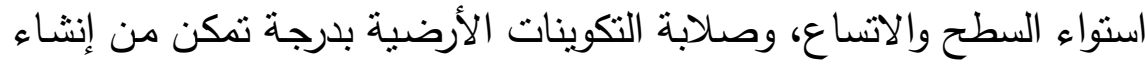

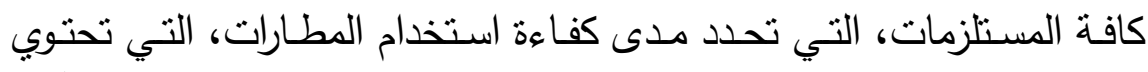

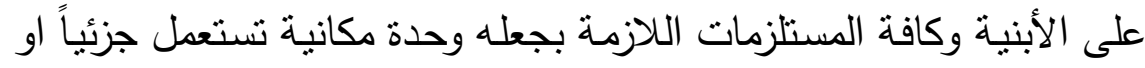

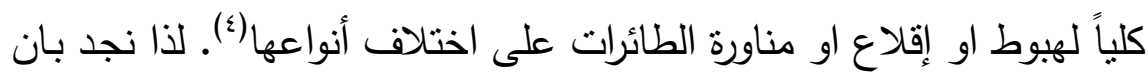

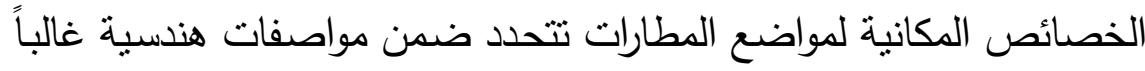

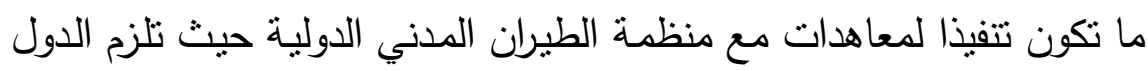

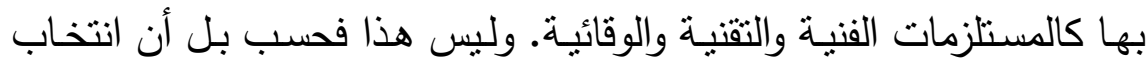

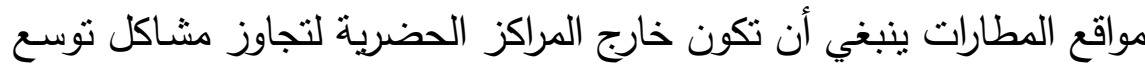

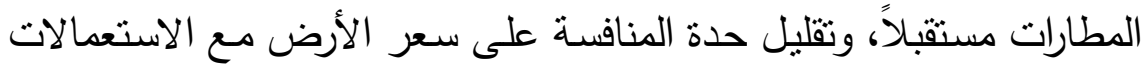

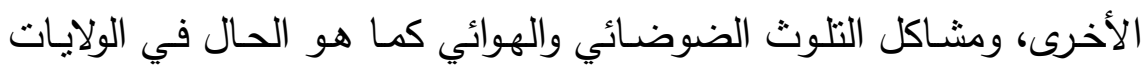

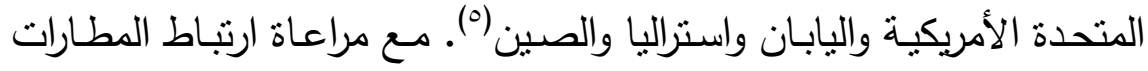




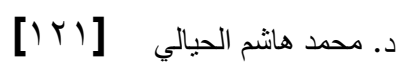

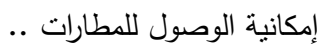

مع مراكز المدن في ظهيرها المباشر وغير المباثر عبر شبكات النقل البري

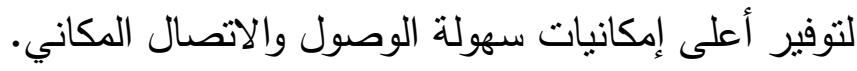

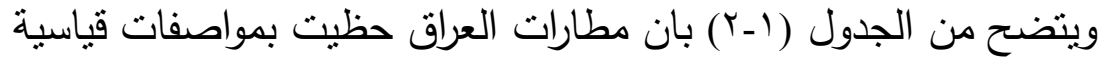

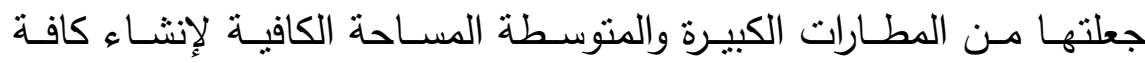

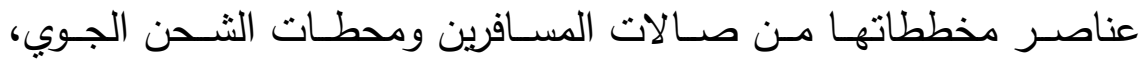

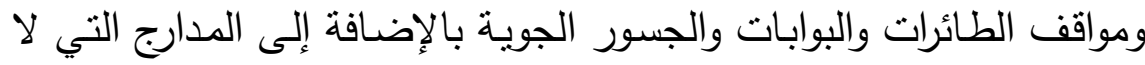

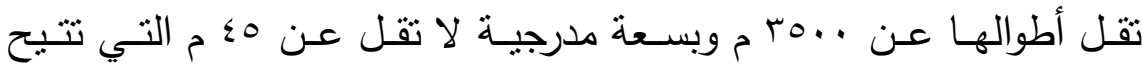

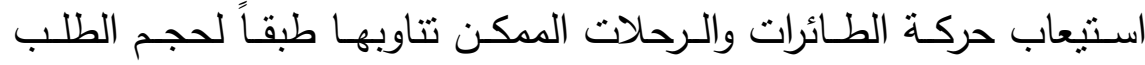

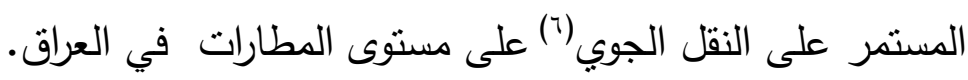
جدول (1-Y) الخصائص المكانية للمطارات الرئيسة في العرلق عام

$(*) r \cdot I r$

\begin{tabular}{|c|c|c|c|c|c|c|c|c|}
\hline \multirow[b]{2}{*}{ الجسوية } & \multirow[b]{2}{*}{ الجوابية } & \multicolumn{2}{|c|}{ صالات المسافرين } & \multicolumn{2}{|c|}{ مدارج المطارات } & \multicolumn{2}{|c|}{ الموضعية } & \multirow[b]{2}{*}{ المطارات } \\
\hline & & مستصميمية & عددها & $\begin{array}{l}\text { أطوالها م ( ) } \\
\text { ( ) }\end{array}$ & عددها & $\begin{array}{l}\text { الارتفاع ( ) } \\
\text { ( ) }\end{array}$ & المدن & \\
\hline 11 & $r$ & vo.. & $r$ & $\begin{array}{l}\text {. . . } \\
\varepsilon . .\end{array}$ & r & ro & 17 & بغداد \\
\hline م & 1 & r... & 1 & ro... & 1 & & & النجف \\
\hline 0 & 1 & $r \ldots$ & 1 & $\varepsilon \ldots$ & 1 & $r$ & $r$. & البصرة \\
\hline م-غ & 1 & $0 .$. & 1 & $\{\ldots$ & 1 & Y14 & 0 & الموصل \\
\hline 17 & $r$ & $r \ldots$ & $r$ & $\begin{array}{l}\varepsilon \wedge \ldots \\
\varepsilon \ldots\end{array}$ & r & \&10 & $v$ & اربيل \\
\hline 17 & $r$ & r... & $r$ & $\begin{array}{l}\text { ro... } \\
\text { ro... }\end{array}$ & r & ११० & 10 & السليمانية \\
\hline
\end{tabular}

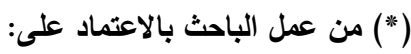

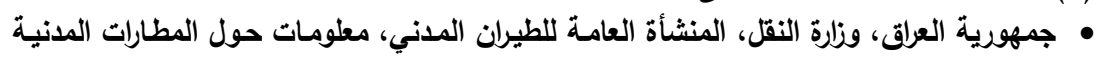

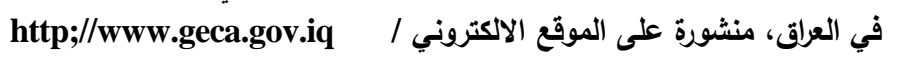


حيث ان مطارات المنـاطق الوسطى حظيت بخصـائص مكانيـة متميزة

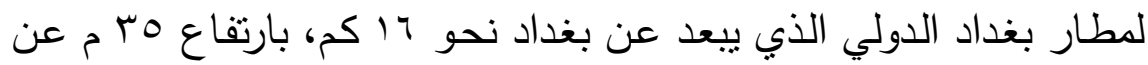

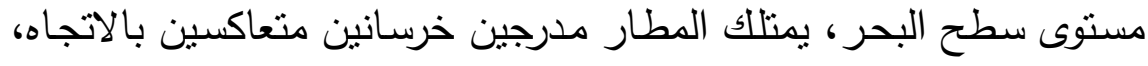

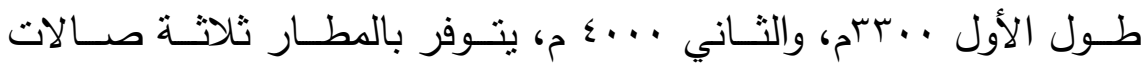

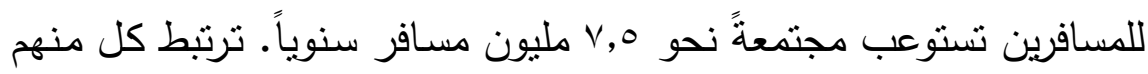

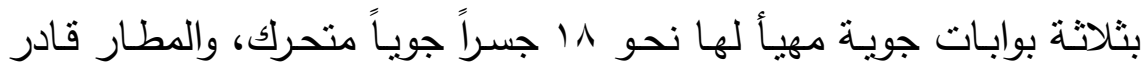

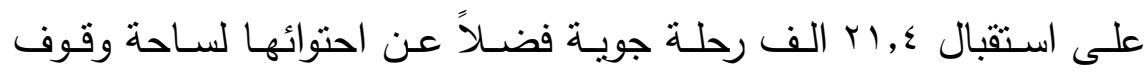
الطائرات وأبنية المراقبة الجوية والاتصال والإطفاء والمخازن. مقارنة بمطار النجف الواقع شرق مدينة النجف اذ يضم المطار صـالة استقبال المسافربن

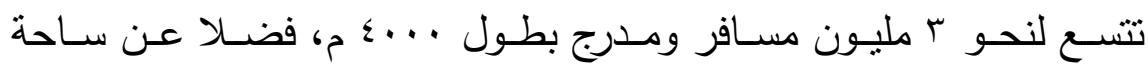
تستوعب أربعة طائرات، والمطار مجهز بكافة المستلزمات الواجب توفرها

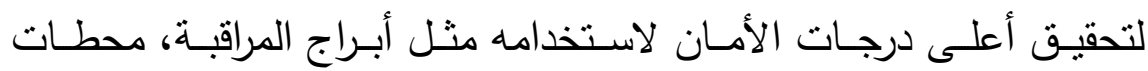
الشحن، مواقف سيارات لذا يعمل بالمطار نحو ، 100 موظفاً.

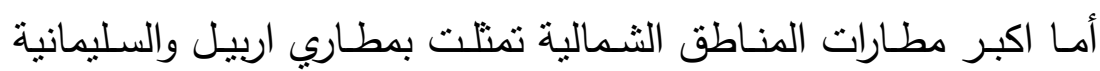
طبقاً لخصائصهما المكانية حيث يبعد مطار اربيل نحو ل كم عن مركز

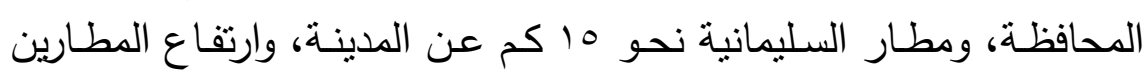

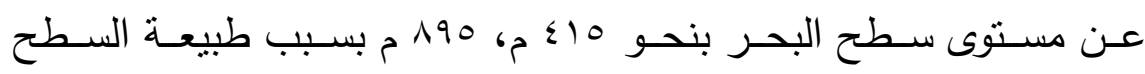

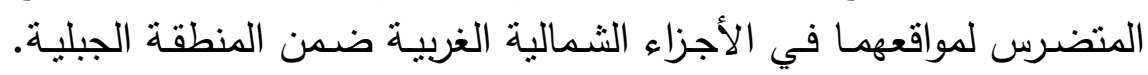
يمتلك المطارين ثلاثة صالات لاستقبال المسافرين وبدرجات رجال الإعمال

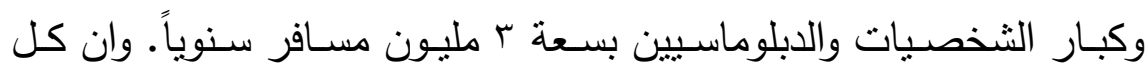

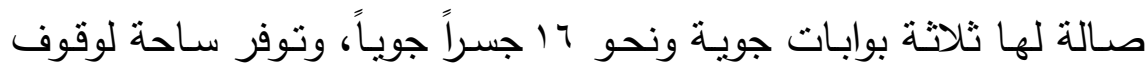

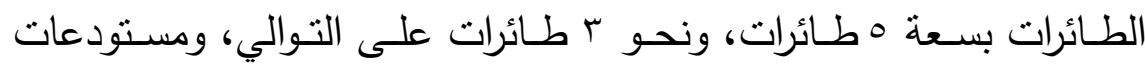

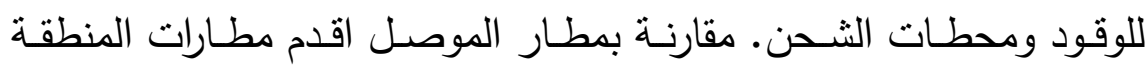

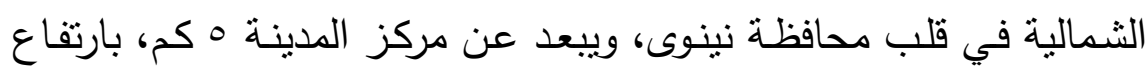

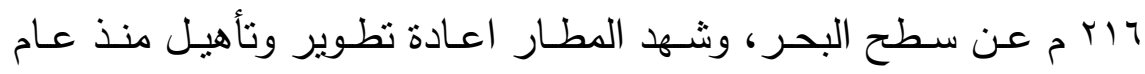




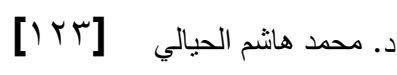

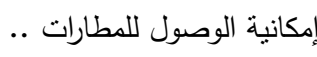

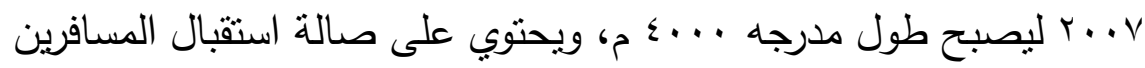

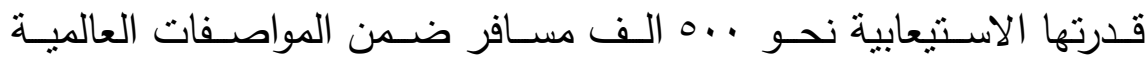
لخدمات الرحلات التجارية الدولية.

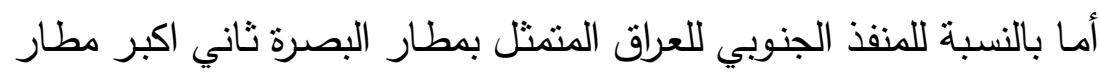

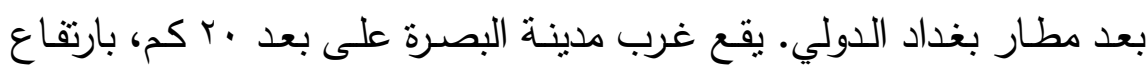

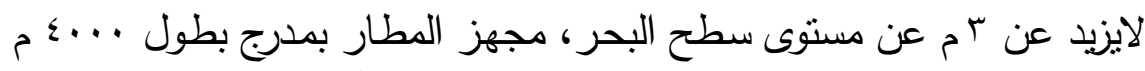

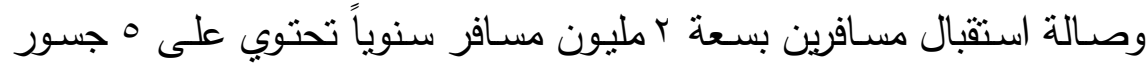

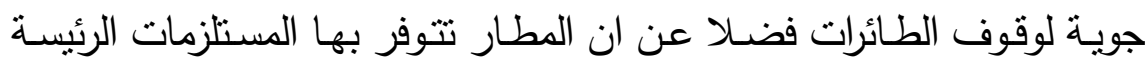
لتامين سلامة الحركة الجوية وتوفير الخدمات للمسافرين.

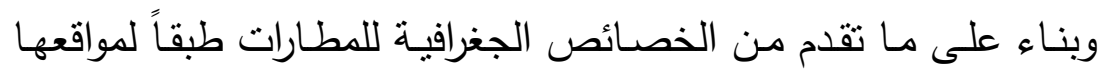

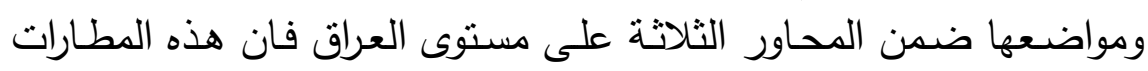

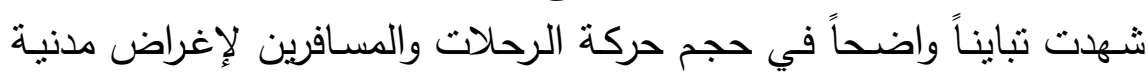

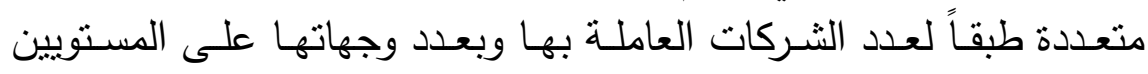

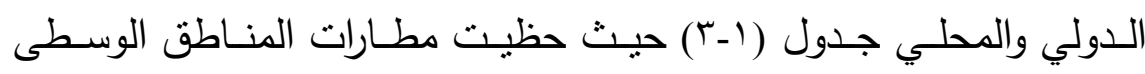

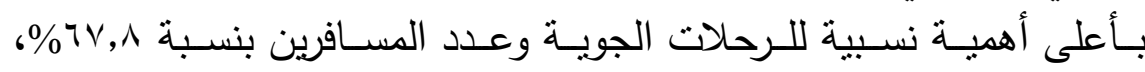

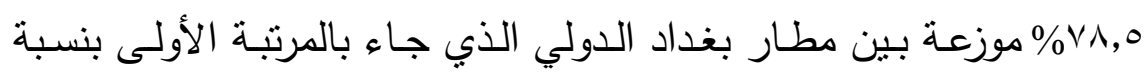

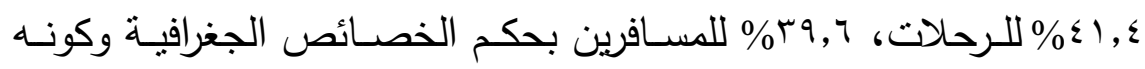

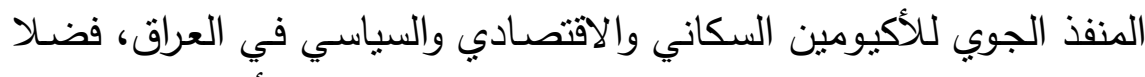

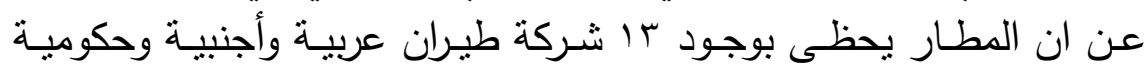

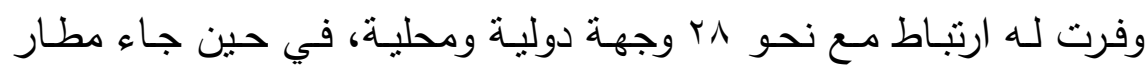

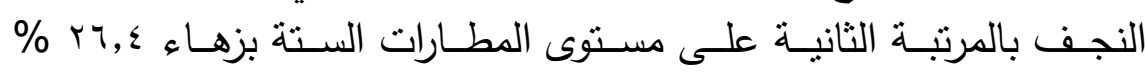

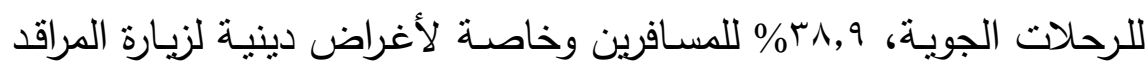

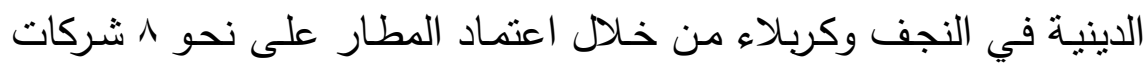
طيران تربطه بنحو ؛ ا وجهة دولية ومحلية. 
دراسات إقليمية • (1) (1)

جدول (1) الأهمية النسبية لحركة النقل الجوي في مطارات العرلق خلال الربع

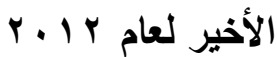

\begin{tabular}{|c|c|c|c|c|c|c|c|c|}
\hline \multicolumn{2}{|c|}{ 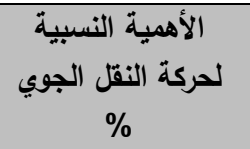 } & \multicolumn{3}{|c|}{ حجم المسافرين } & \multicolumn{3}{|c|}{ الرحلات الجوية } & \multirow[t]{2}{*}{ المطارات } \\
\hline المسافرين & الرحلات & المجموع & المغادرون & القادمون & المجموع & المغادرة & القادمة & \\
\hline$r q, 7$ & $\leqslant 1, \varepsilon$ & אוזוז & I YAr & IrVVar & $\varepsilon 1 \times q$ & $r \cdot V r$ & $r .74$ & بغداد \\
\hline$r \wedge, q$ & rY, & หษ। & Irrq.0 & irvaqr & $r q \varepsilon r$ & Irr. & Irrs & التجف \\
\hline $1 \leqslant, 0$ & $1 v, 9$ & $q \vee r \leq \varepsilon$ & \& צ Yr & D.VYr & $1 \vee 9$. & 190 & 190 & البصرة \\
\hline $1, r$ & $1, r$ & 9.17 & P & OHY & Irr & 71 & 94 & الموصل \\
\hline$r$ & $7, \varepsilon$ & $19 \wedge \leq r$ & $90 \wedge 9$ & 1. ror & $7 \varepsilon$. & r. & rr. & اربيل \\
\hline$r, v$ & $7, \mathrm{~V}$ & IV^०\& & Novo & qrvq & $7 V$. & ס סrr & סמrr & السليمانية \\
\hline $1 \ldots$ & $1 \ldots$ & IVY.TI & rr.Vro & צrolru & $1 \ldots \varepsilon$ & $\leq 99 \leqslant$ & 0.1. & الاجمالي \\
\hline
\end{tabular}

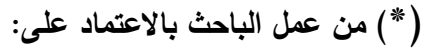

• مهورية العرق، وزارة النقل، المنثأة العامة للطيران المدني، حركة الطيران المدنية في المطارات العراقية،

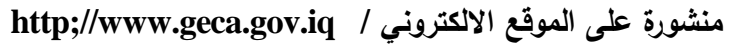

ناهيك عـن أن المنفـذ الجـوي الجنـوبي للعـراق المتمثل بمطـار البصـرة

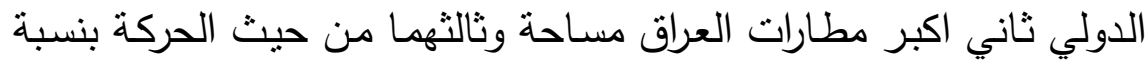

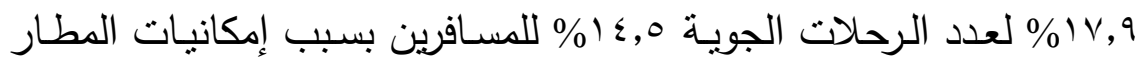
في توفير المناخ الجيد لعمل نحو rا شركة طيران وارتباطه بنحو لوجهات

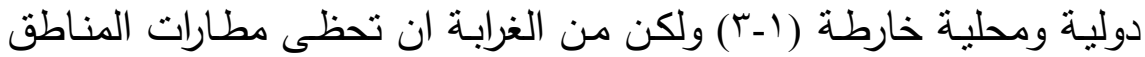

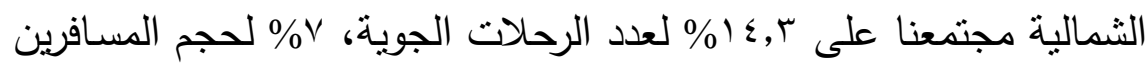
من إجمالي حجم حركة النقل الجوي بالمطارات الست الرئيسـة في العراق خلال الربع الأخير لعام r إ.r. خاصـة مطارات اربيل والسليمانية الدوليين

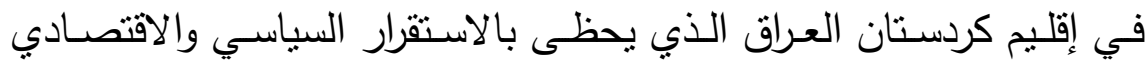

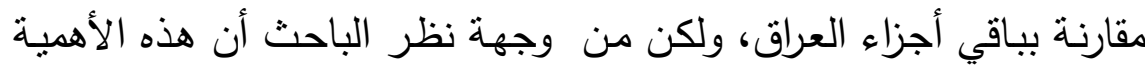
النسبية القليلة قد تكون بسبب تأثثر المناخ كون البيانات المتوفرة جاءت وجنه 


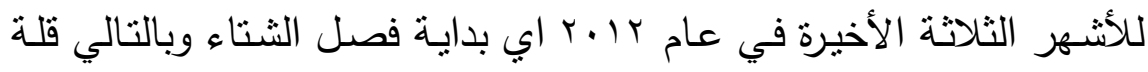

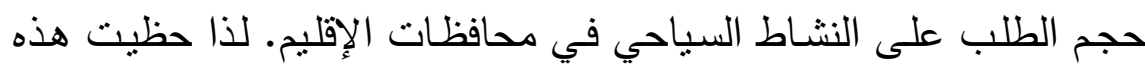

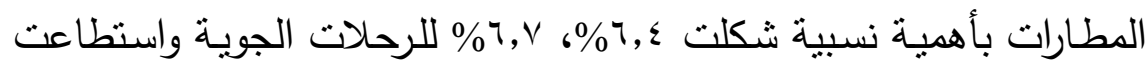

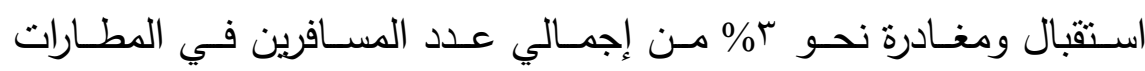

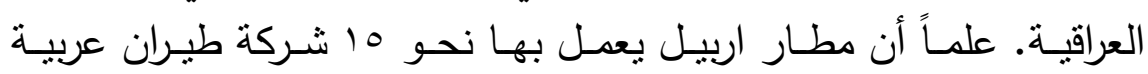

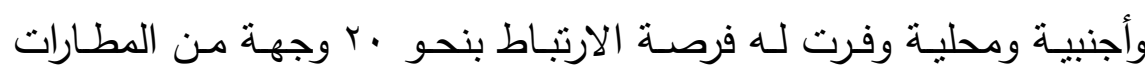
الدولة والمحلية. أما بالنسبة لمطار الموصل الحديث العهد في الاستخدام لإغراض النقل

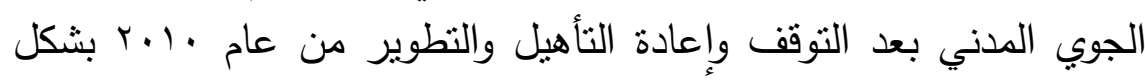

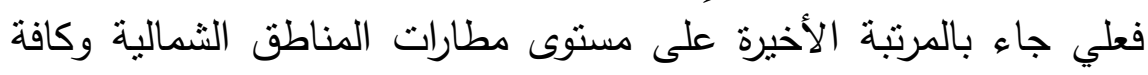

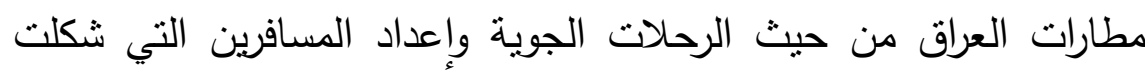

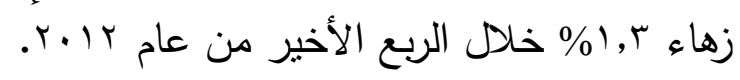

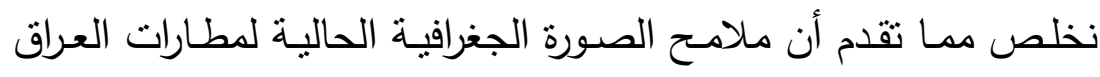

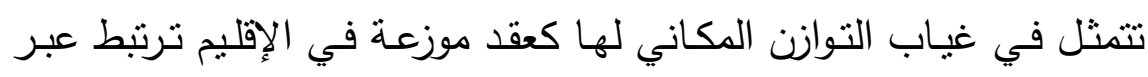

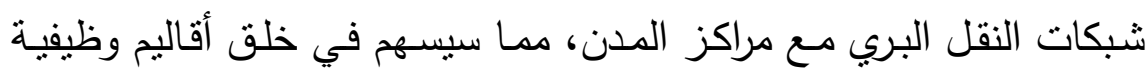

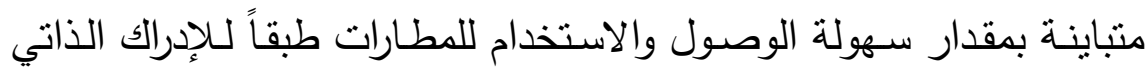

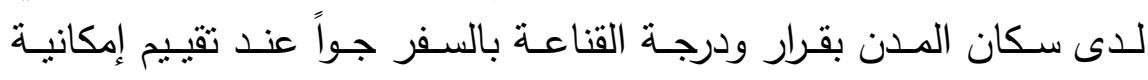
الوصول للمطارات لاحقاً. 


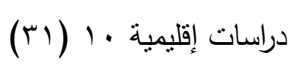

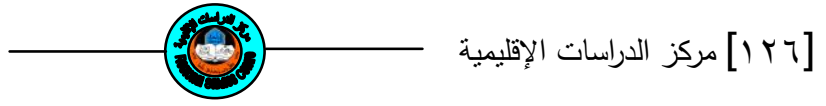

خارطة (1-r): التوزيع المكاني لحركة النقل الجوي حسب المطارات الرئيسة في العراق

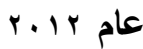

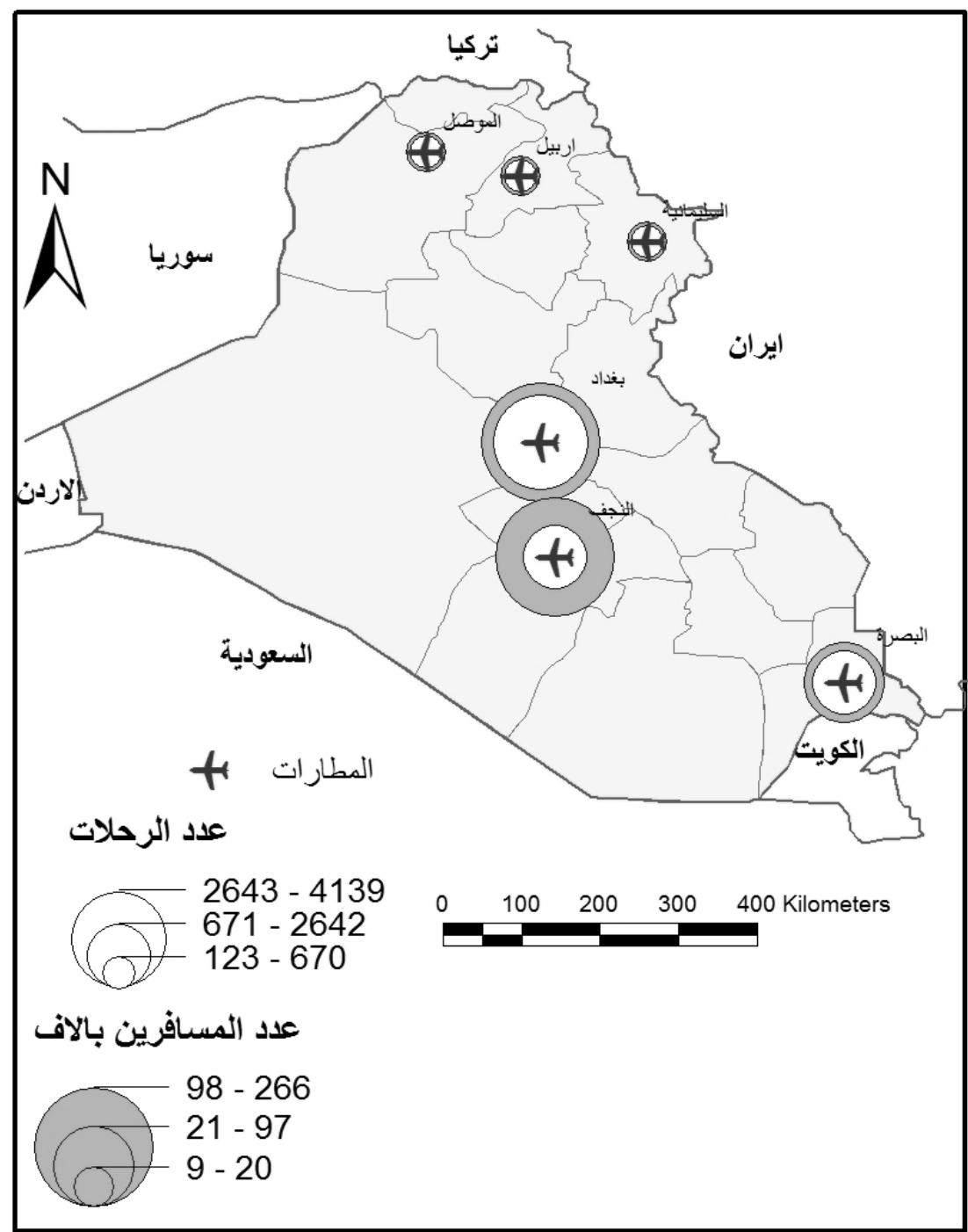




\section{r. تقييم إمكانية الوصول للمطارات الرئيسة في العرلق}

تعد إمكانية الوصول من المؤشرات التي تقصح عن مدى عمق العلاقة الوظيفية التبادلية بين كافة العقد النقلية عامة والمطارات خاصـة مـع ظهيرها

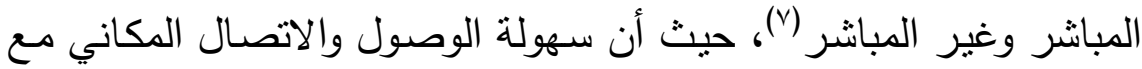

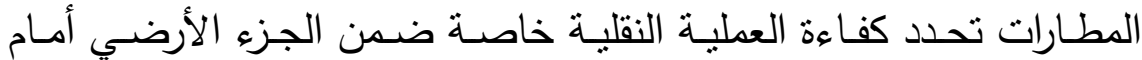
حركة المسافرين او البضائع او عناصر الإنتاج من والى المطارات باتجاه

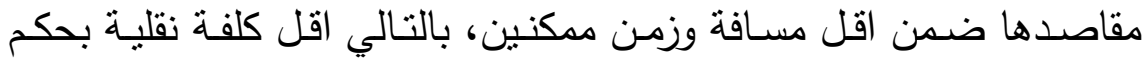

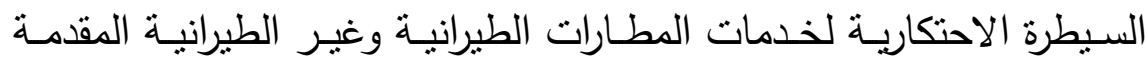
لشركات الطيران التي تمثل زبائنها الأساسبين، ولدور الأخيرة في تحديد

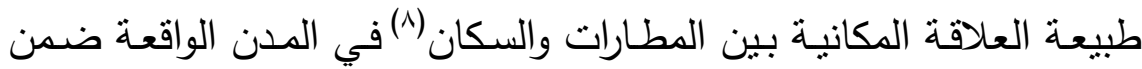

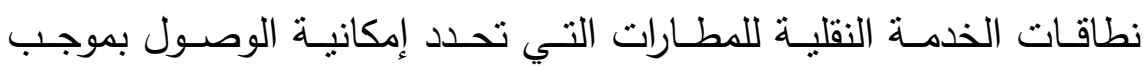
المسافة الفاصلة بين المطارات وظهيرها من المدن. وتأسيساً عليه تم الاعتماد في تقييم إمكانية الوصول الى المطارات الست الته

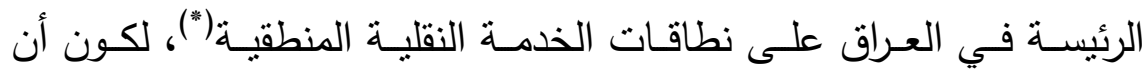
الخدمات النقلية للمطارات لا تتحصر فقط على المسـافة التقليديـة الأقصر

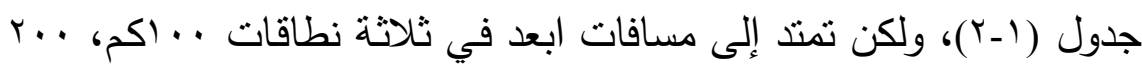
كم، .r كم. حيث أن هذه النطاقات تفصح عن الكيفية التي يكون المطار عقدة نقلية مريحة وسهلة الوصول والاستخدام من قبل سكان المدن، وبالتالي

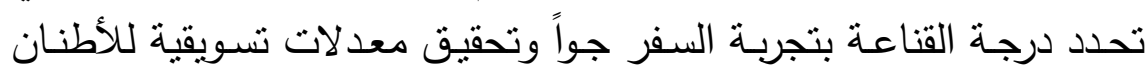
الكيلومترية المعروضة من قبل شركات الطيران العاملة بالمطارات.

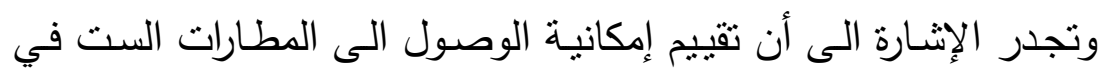

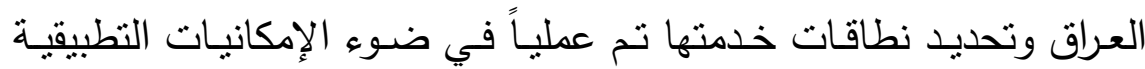
لتقانة برنامج Google Earth الذي اعتمد في تحديد مواقع المطارات والمدن

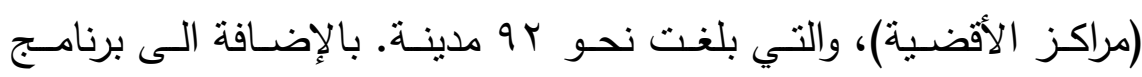

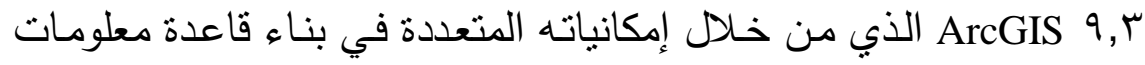




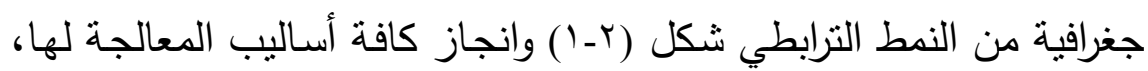

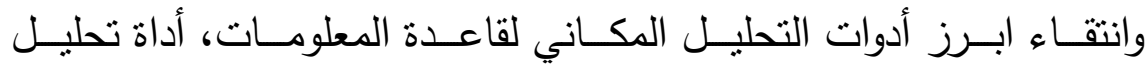

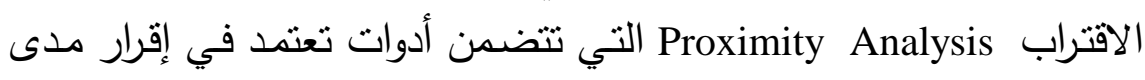

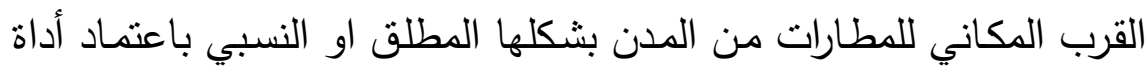

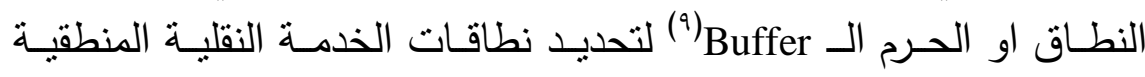

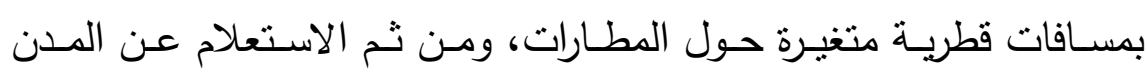

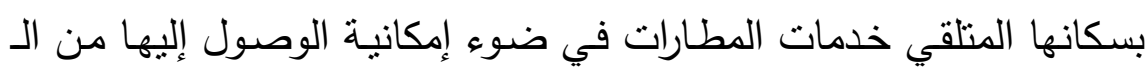

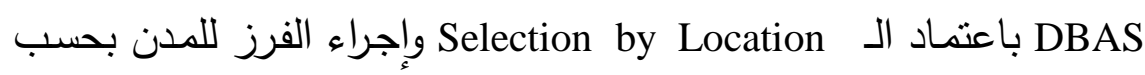

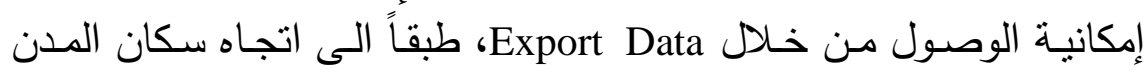

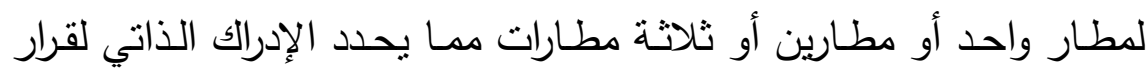

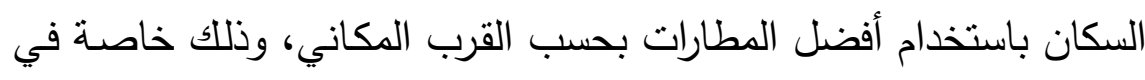

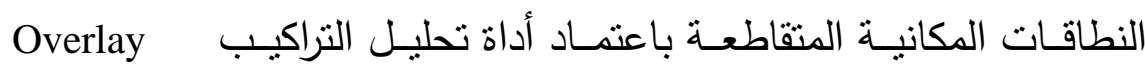

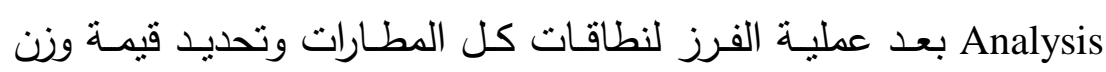

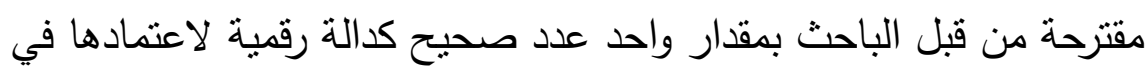

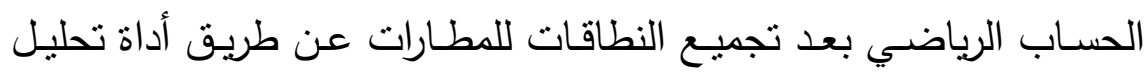

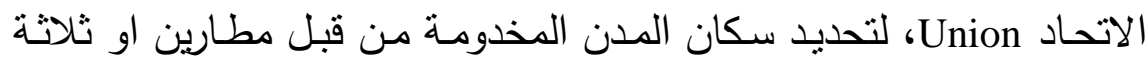

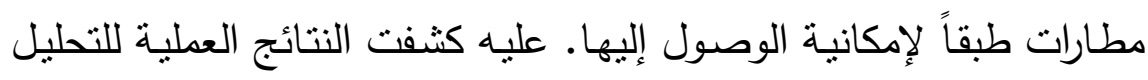

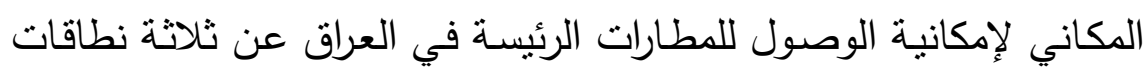

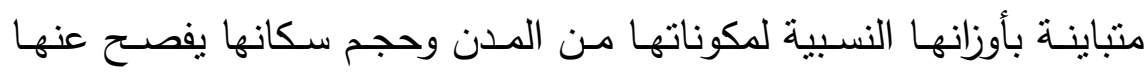

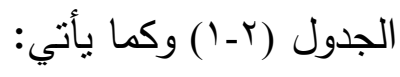

شكل (r-1) قاعدة بيانات لإمكانية الوصول للمطارات الرئيسة في العرلق 


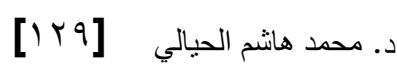

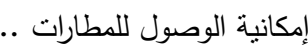

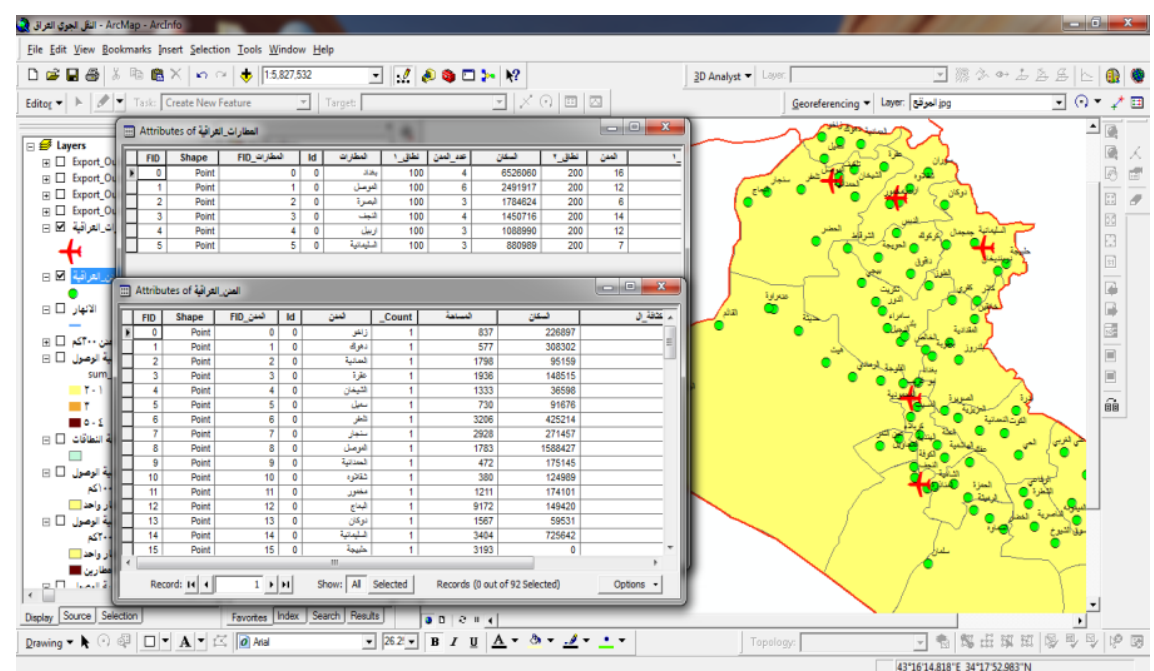

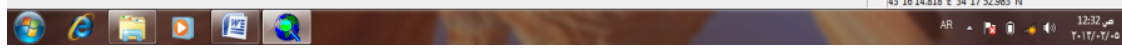

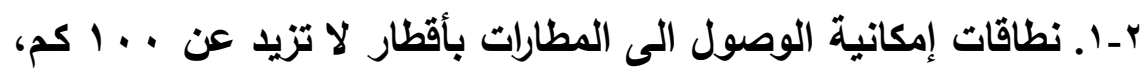

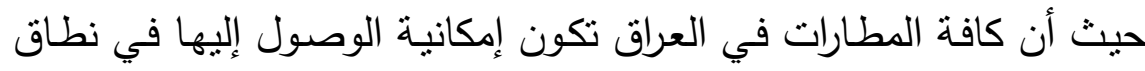

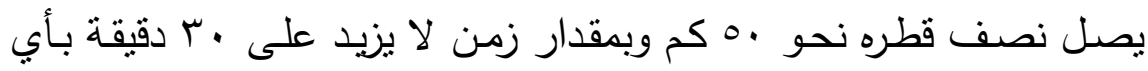

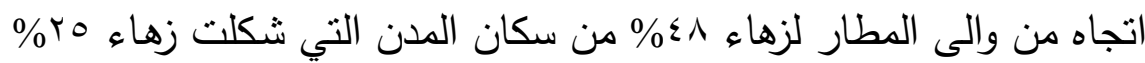

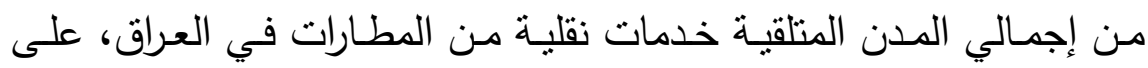

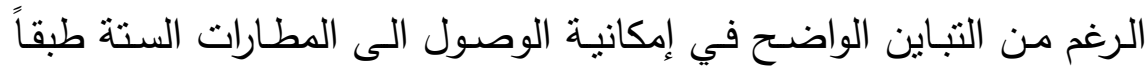

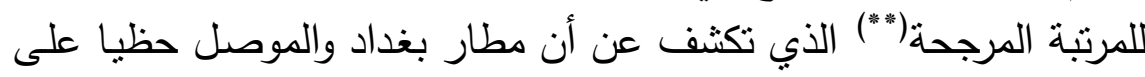

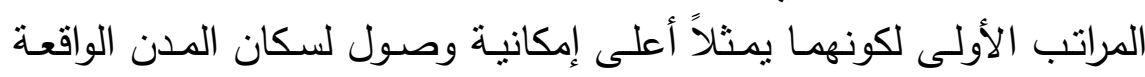

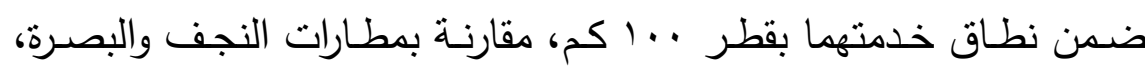

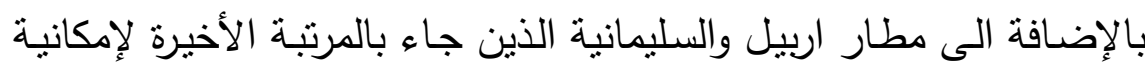

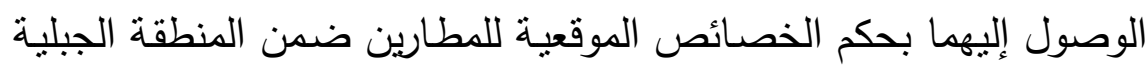

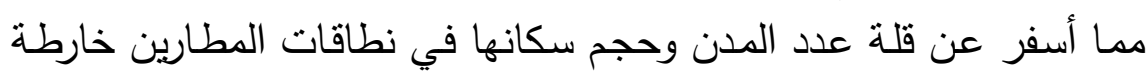


دراسات إقليمية . 1 ( آب)

[ [1 ] مركز الدراسات الإقليمية 


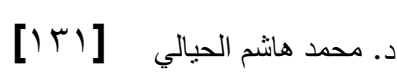

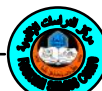

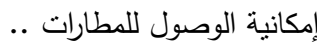

خارطة (r-1) نطاقات إمكانية الوصول للمطارات الرئيسة في العرلق

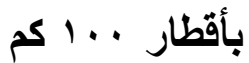

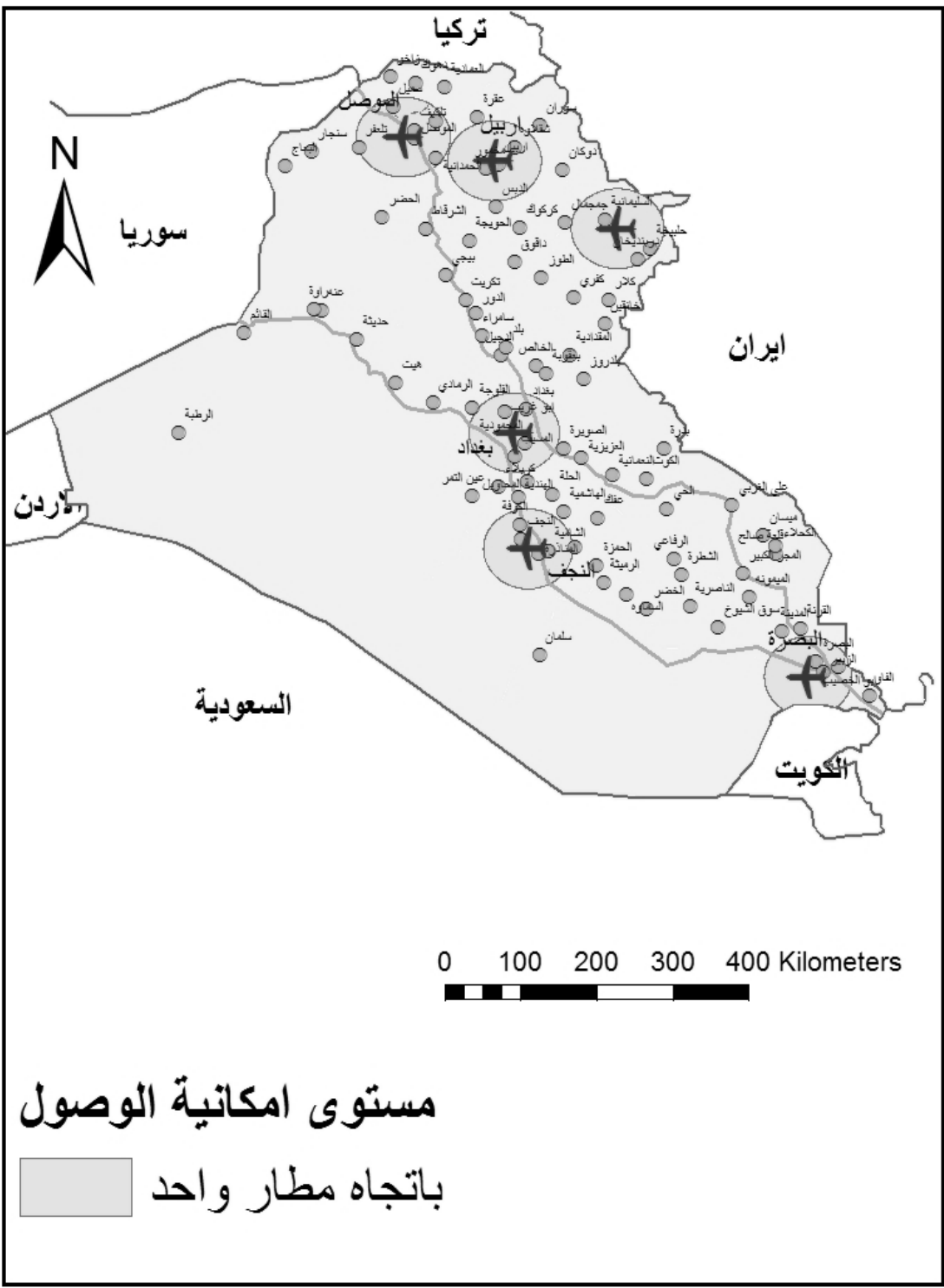




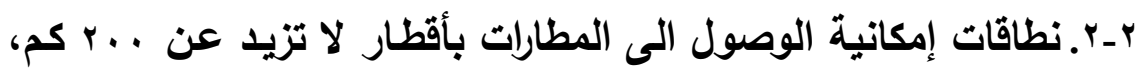

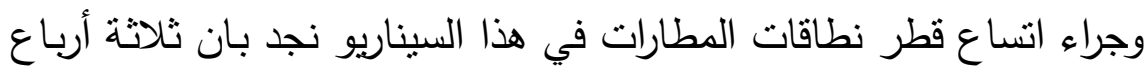

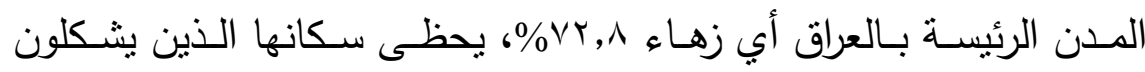

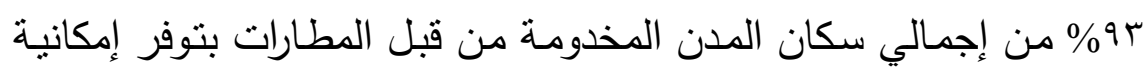

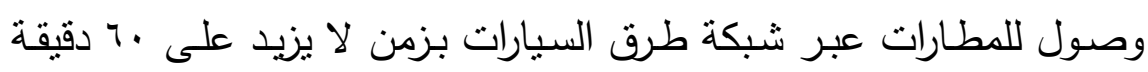

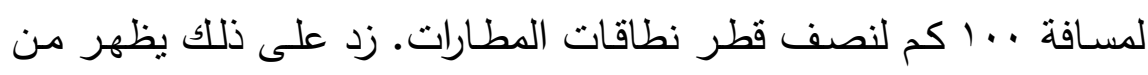
الخارطة (r-r) بان هناك تداخل بنطاقات المطارات مما يسفر عن أن هناك فئك

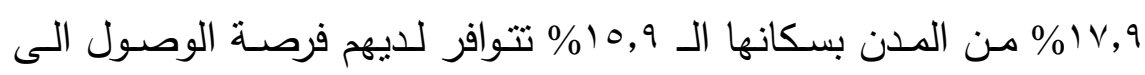
مطارين بزمن لا يزيد عن ·ـ دقيقة. وطبقاً للأهميـة النسبية التي حصلت عليه المطارات لإمكانيـة الوصسول بحسب مراتبها المرجحة نجد بان مطارات المنطقة الوسطى بغداد والنجف ولفه

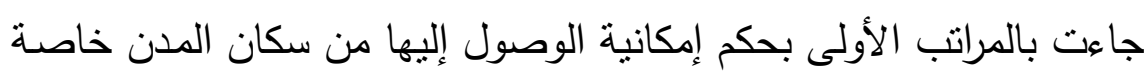

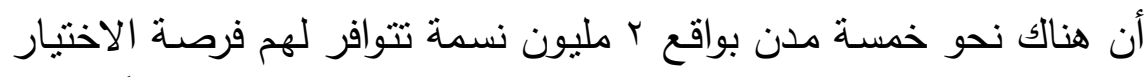
بين المطارين، بالتالي يؤدي ذلك الى زيادة درجة القناعة بالسفر جواً لسكان التهان

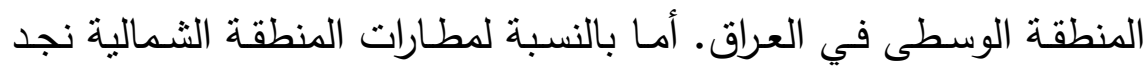

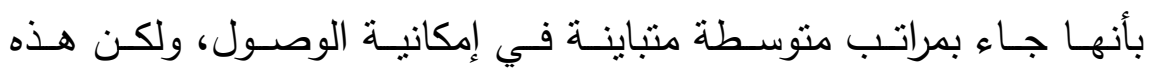

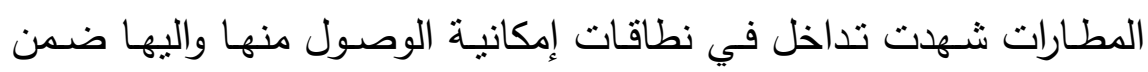

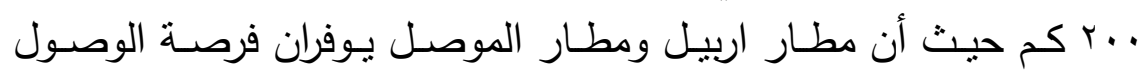

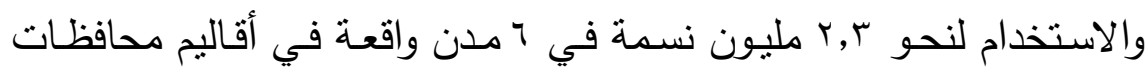

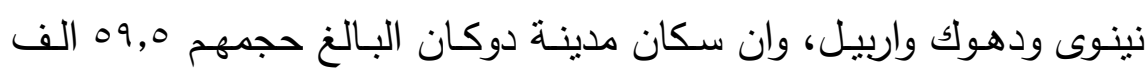

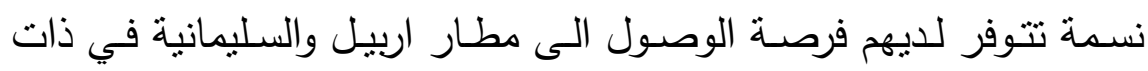
الوقت، وبهذا يعتبر مطـار اربيـل أســل المطـارات في المنطقـة الثـمالية بحسب المرتبة المرجحة لإمكانية الوصول الى المطار وتقاطعه مع نطاقات

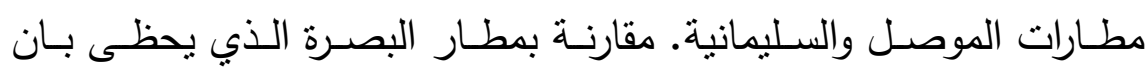




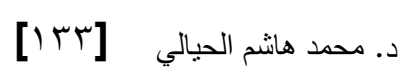

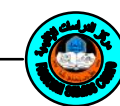

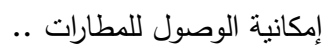

إمكانيـة الوصـول أليهه مـن نحو 1 مدن في محافظـة البصـرة والمحافظـات

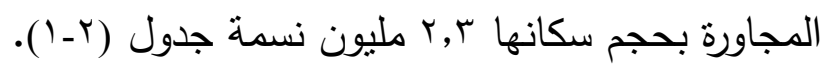

خارطة (r-r) نطاقات امكانية الوصول للمطارات الرئيسة في العرلق

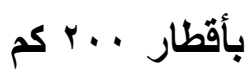

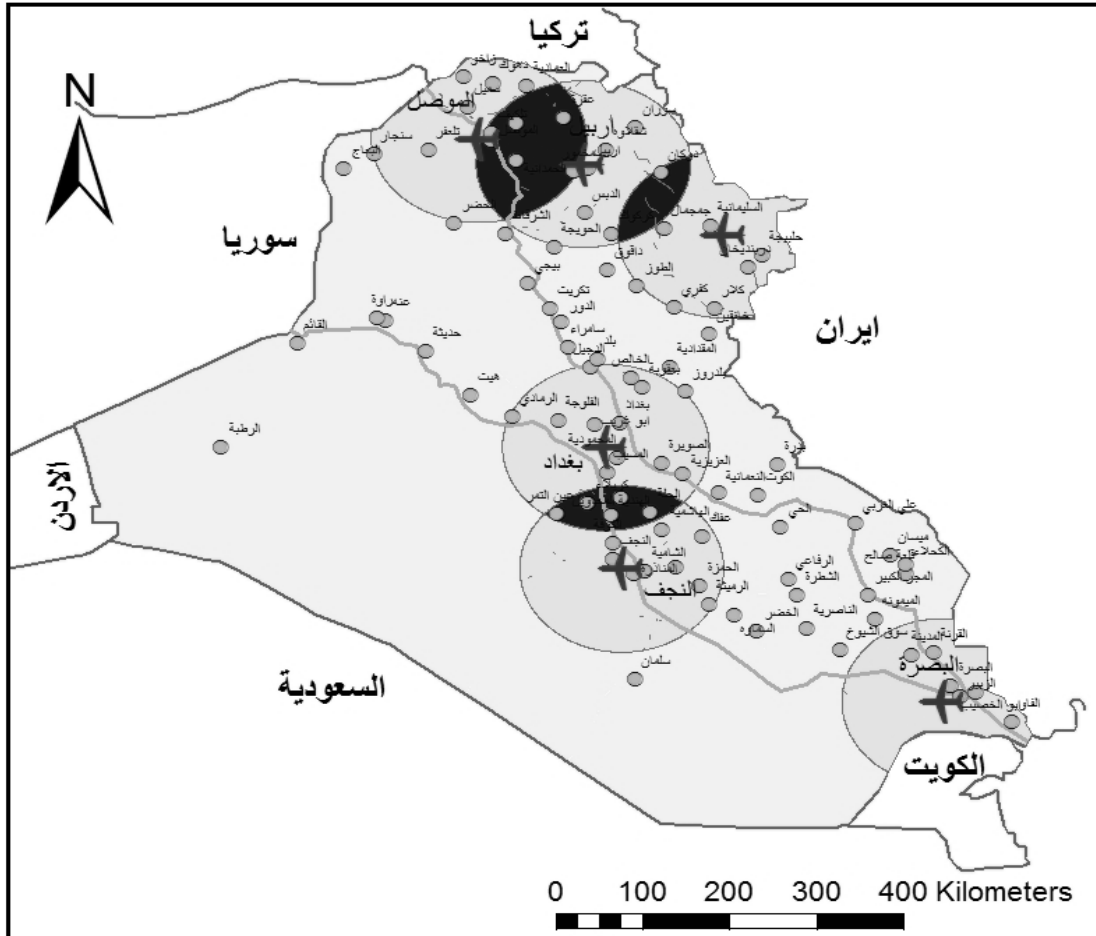

مستويات امكاتية الوصول

باتجاه مطار و احد

باتجاه مطارين 


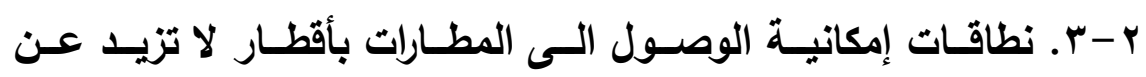

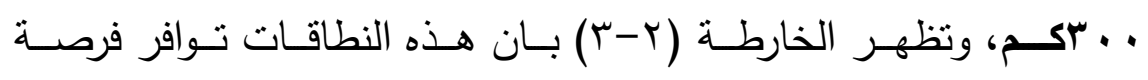

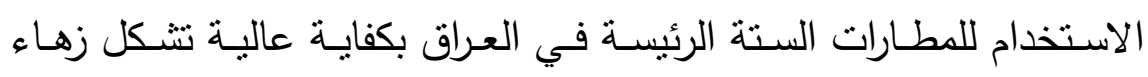

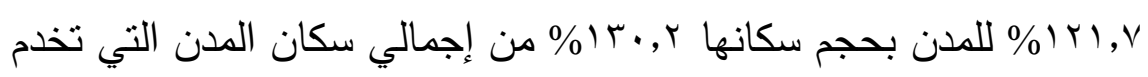
من قبل المطارات، ولكن تعتبر هذه النطاقات ذو كفاءة قليلـة في امكانية الهية

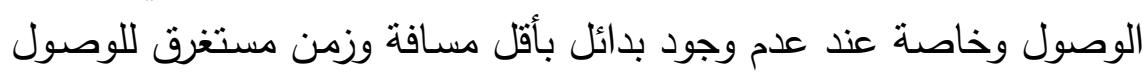

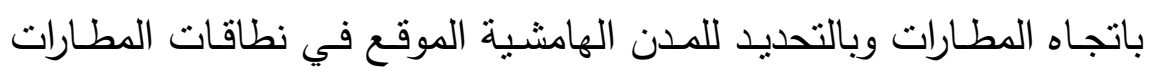
التي يحتاج سكانها للوصول من والى المطارات في أنصاف أقطارها بـأي

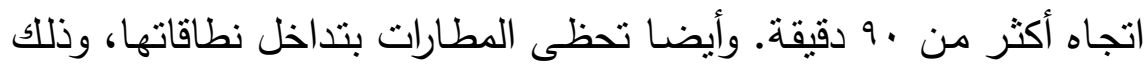

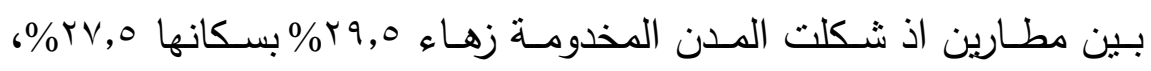

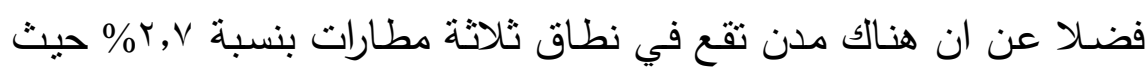

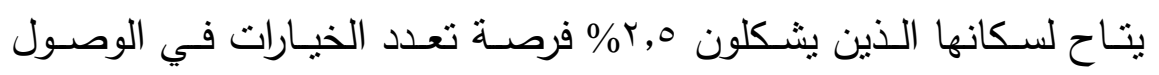
واستخدام المطارات في زمن يتراوح بين • ــ • ج دقيقة. 


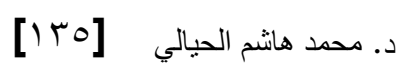

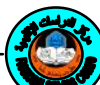
إمكانية الوصول للمطارات ..

خارطة (r-r) نطاقات إمكانية الوصول للمطارات الرئيسة في العرلق

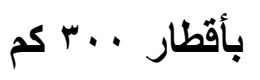

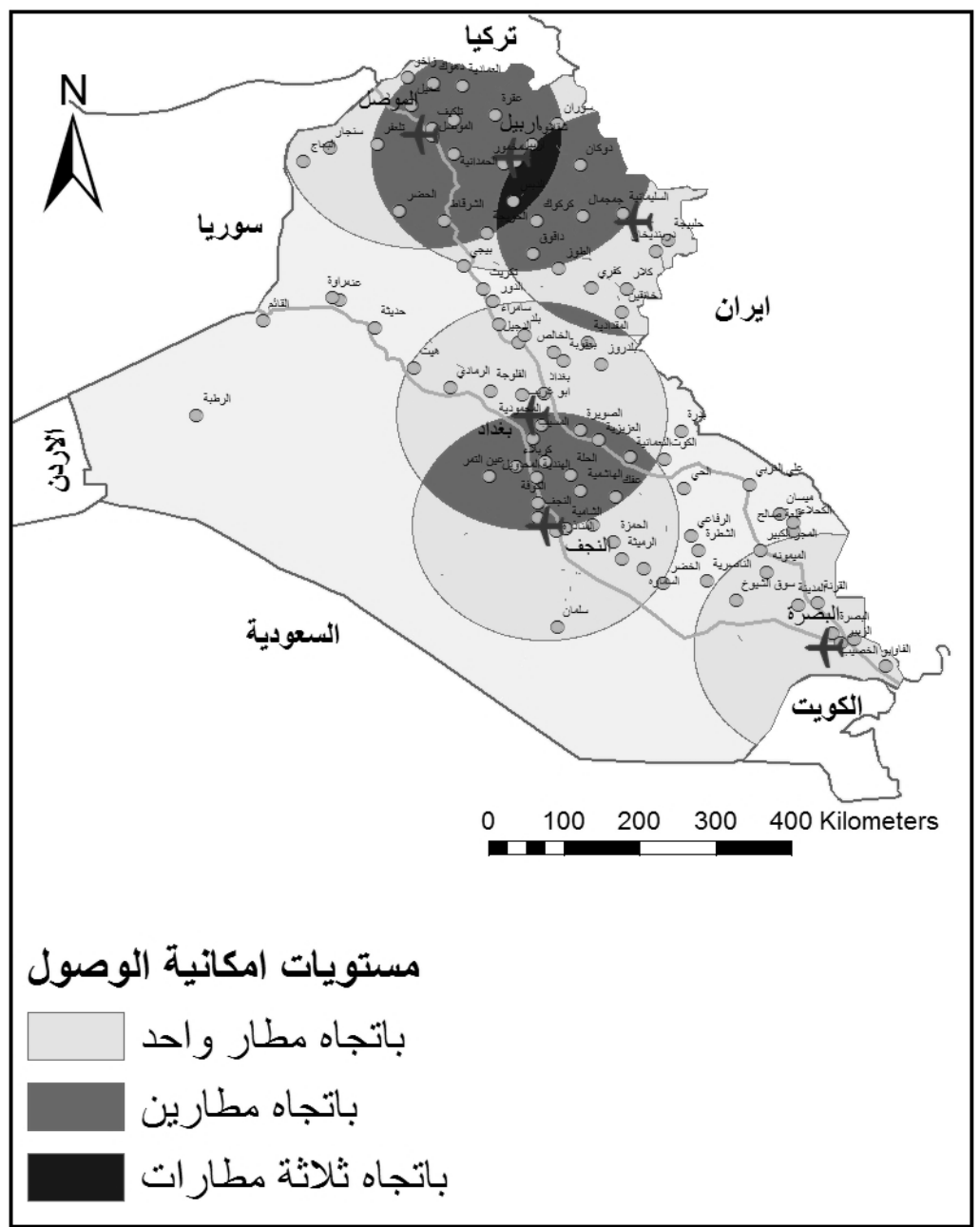

وتتشه مطارات العراق تباين طبقاً لنطاقات إمكانية الوصول ألبها ذات

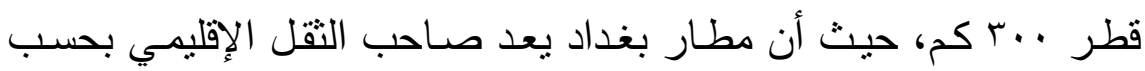

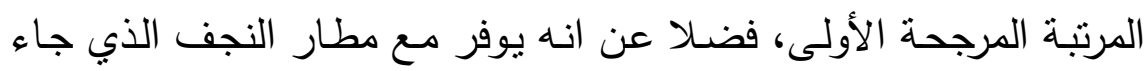


بالمرتبة الثالثة لنحو ع ا مدينة يبلغ حجم سكانها نحو ^,ـء مليون نسمة من

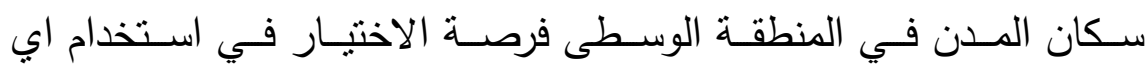
المطارين. في حين مطار اربيل صـاحب المرتبة المرجحة الثانيـة لإمكانية

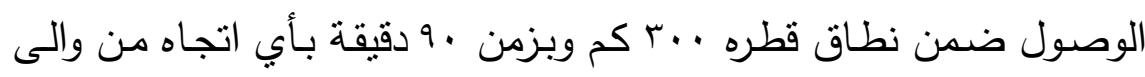
المطار ، يتميز جراء تقاطع نطاقه مع نطاقات مطار الموصل والسليمانية

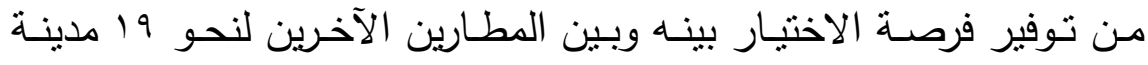

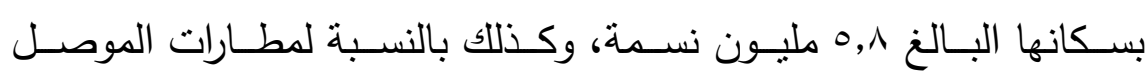
السليمانية الحاصلة على المراتب المرجحة الرابعة والخامسة لإمكانية وصول بالئل

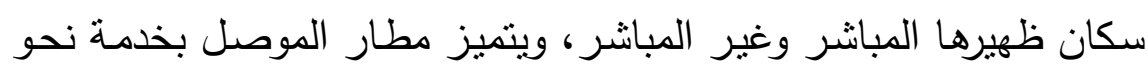

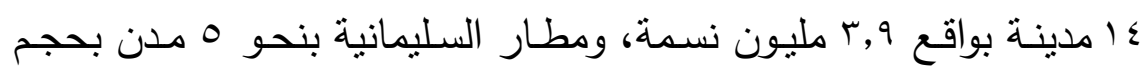
سكان يصل الى 9, أ مليون نسمة، الواقع بنطاقاتهم المتقاطعـة مـع مطار

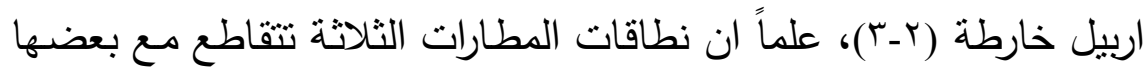

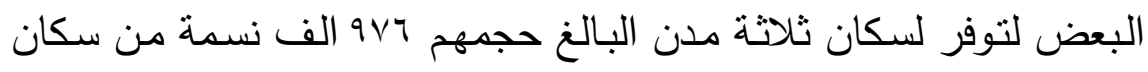

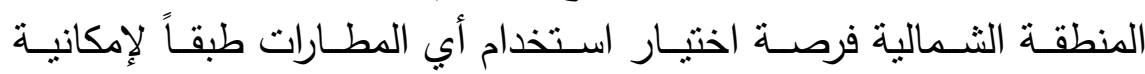

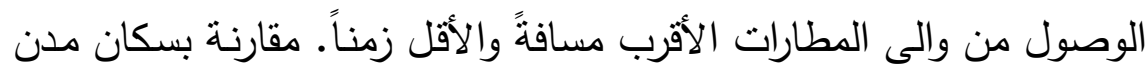
المنطقة الجنوبيـة التي لا تتوفر لـديها فرصـة الوصـول إلا باتجـاه مطـار

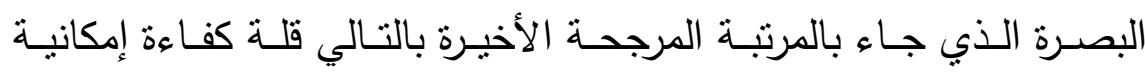
الوصول.

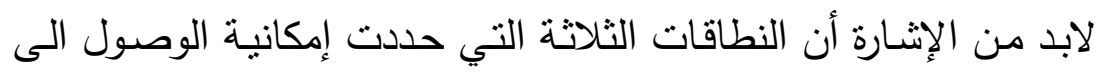

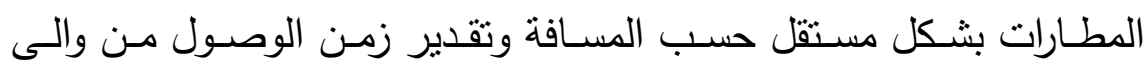

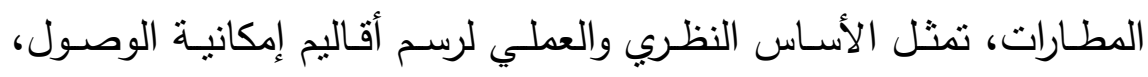
وتحديد مستويات الإدراك الذاتي لقرار السكان باستخدام المطارات، وماهية المتطلبات التخطيطية الملزمة للصورة المنتظرة لإمكانية الوصول للمطارات 


\section{r. أقاليم إمكانية الوصول للمطارات الرئيسة في العرلق}

تعد أقاليم إمكانيـة الوصـول من الأقاليم الوظيفيـة ومن أسـاليب النمذجـة

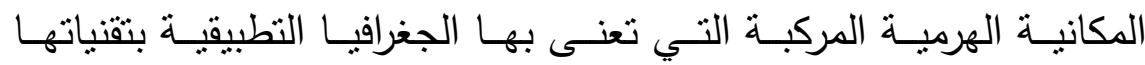

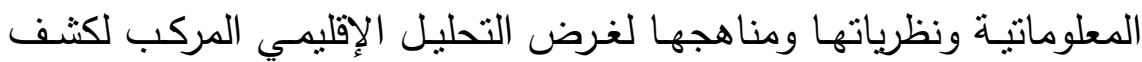

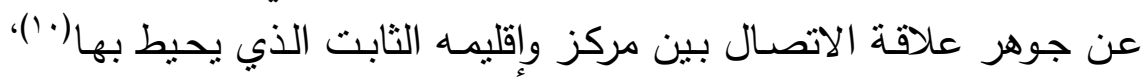

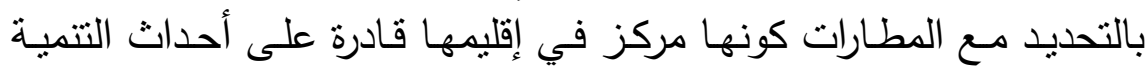
الاقتصادية والاجتماعية والحضارية من خلال تعظيم العلاقات المكانية بين

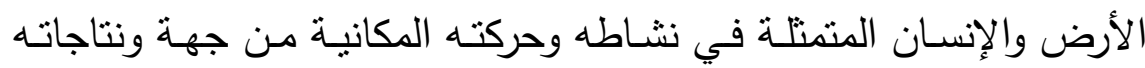
الإنتاجية والخدمية من جهة أخرى مما يحقق التوازن والتجانس في أقاليمها

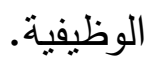

وبغية الكثف عن أقاليم إمكانية الوصول للمطارات الستة في العراق تم الاعتمـاد على العلاقات البنيويـة في الاتصـال بين المطارات في نطاقاتها

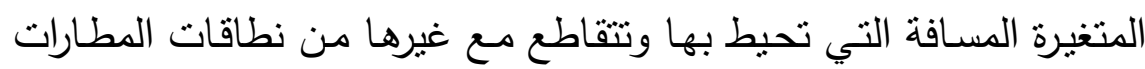
الأخرى، لتحديد الأقاليم الوظيفية لها عند المدن التي لا يزيد تأثرها بمطار

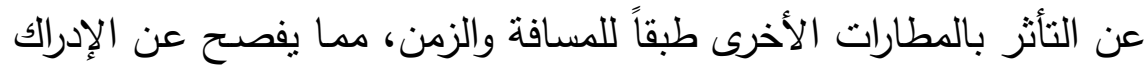

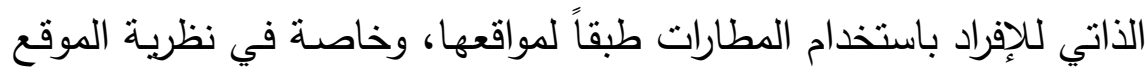

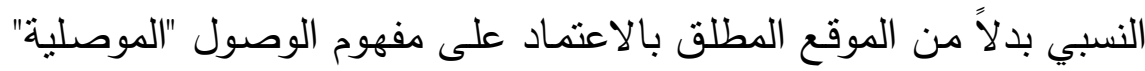
Accessibility

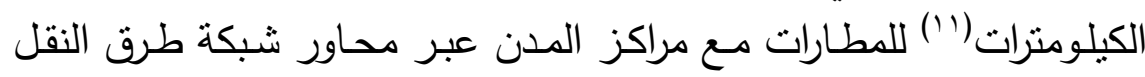

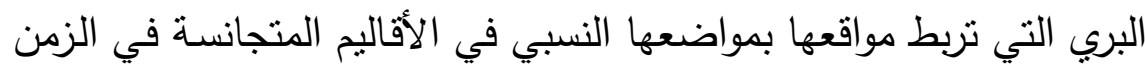
والمسافة في الوصـول بـالرغم من اختلاف خصائصسها الوظيفية الأساسية. ومن تحليل الجدول (r-1)، والخارطة (r-1) نستتتج بان هناك ثلاثثة أقاليم لإمكانية الوصول للمطارات الرئيسة في العراق:- 
r-1. إقليم إمكانية الوصول عاليـة: يشمل هذا الإقليم على نحو بr مدينة

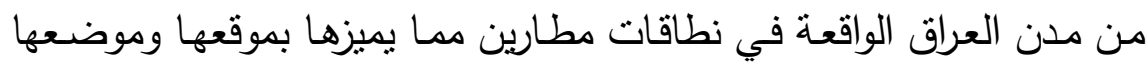

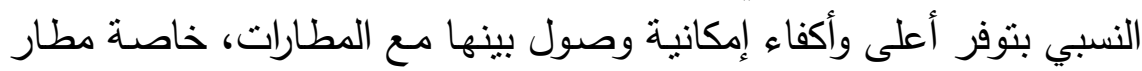

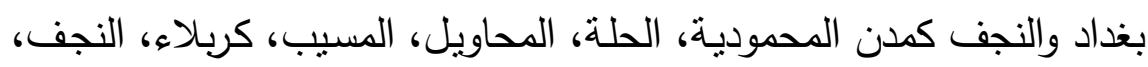

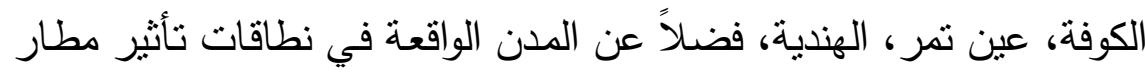

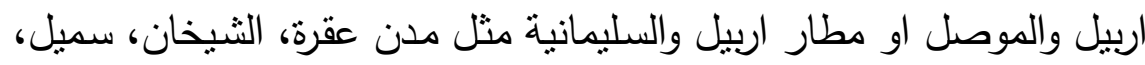

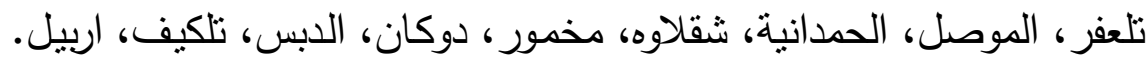

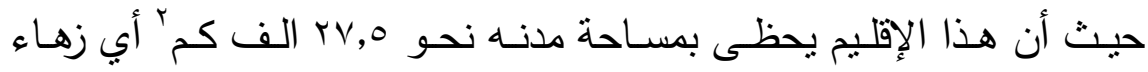

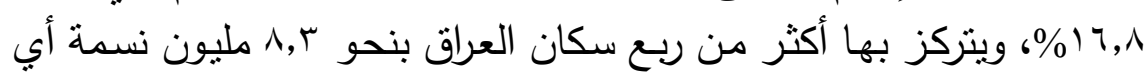

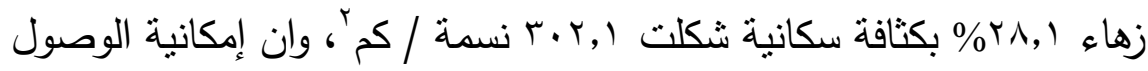
العالية لسكان مدن هذا الإقليم توفر إدراك ذاتي لدى لاء الأفراد بتعدد الخيارات

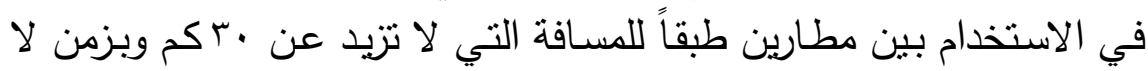
يتجاوز · · دقيقة بأي اتجاه نحو المطارات.

r-r. إقليم إمكانية الوصول متوسطة: يتمثل الإقليم بالنطاقات التي تحيط

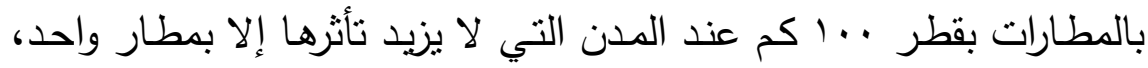

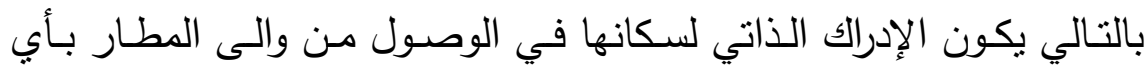

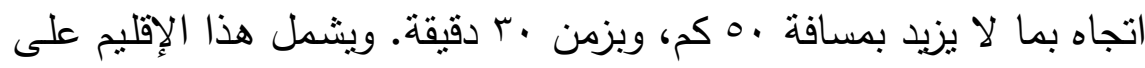

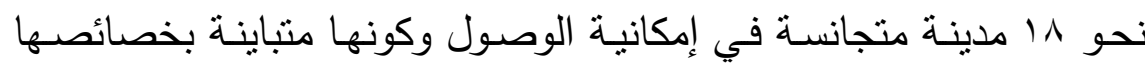

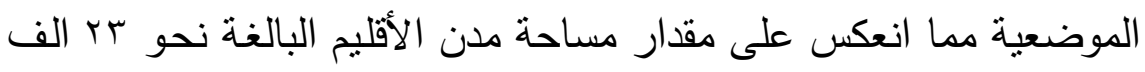

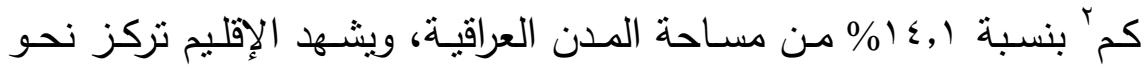

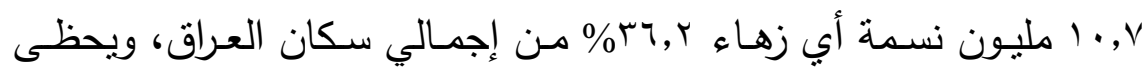

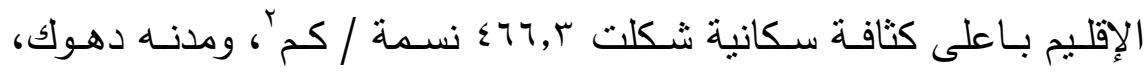

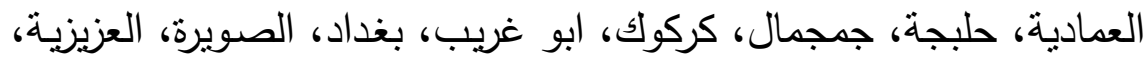
عفك، الهاشمية، ابو الخصيب، الزبير،البصرة، المناذرة، سوران، دربنديخان، 


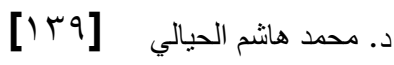
إمكانية الوصول للمطارات ..

جدول (ب- 1 ) أقاليم أمكانية الوصول للمطارات الرئيسة في العراق (")

\begin{tabular}{|c|c|c|c|c|c|c|c|c|c|}
\hline نسمة/كمثانية & مدن الأقاليم & مساحة & أمكانية & \multirow[t]{2}{*}{$ت$} & نسمة/كمثربة السكافة & مدن الأقاليم & مساحة & ألوكانية & \multirow[t]{2}{*}{$ت$} \\
\hline & \multicolumn{3}{|c|}{ اقليم امكانية وصول قليلة } & & & \multicolumn{3}{|c|}{ إقليم إمكانية وصول عالية } & \\
\hline$r V_{1}, \cdot \Lambda$ & rYqAqV & $\Lambda F V$ & زاخو & 1 & $\vee \vee, \vee 1$ & $1 \leq 1010$ & 1947 & عقرة & 1 \\
\hline qr,VI & $r V I \leq 0 V$ & rqrA & سنجار & $r$ & $r V, \leqslant q$ & $r 9091$ & ITrT & الشيخان & $r$ \\
\hline 17,49 & $1 \leq 9 \leq 4$. & qIVY & البعاج & $r$ & $1 Y 0,01$ & $917 V 7$ & VT. & سميل & $r$ \\
\hline $1 r \leq, 4$ & Y091 $\leq 9$ & $19 . r$ & الحويجة & $\varepsilon$ & IrY,T & EYOYI & $r Y \cdot T$ & تلاعفر & $\varepsilon$ \\
\hline$V I, Y Y$ & ATrVH & $11 \mathrm{~V}$. & داقاق & 0 & $\wedge q \cdot, \wedge \vee$ & $10 \wedge \Lambda \leq Y V$ & IVAr & الموصل & 0 \\
\hline IrI,Ir & 1Aro. & 1010 & الشرقاط & 9 & rvi,.v & $\mid v 01 \leq 0$ & $\varepsilon V Y$ & الحمدانية & 7 \\
\hline $0, \cdot V$ & 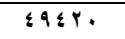 & $9 \vee r \wedge$ & الحضر & $\mathrm{V}$ & $r Y \wedge, q r$ & $1 Y \leq 9 \wedge 9$ & $r \wedge$. & شقلاوة & $\mathrm{V}$ \\
\hline$V \leqslant, 90$ & $17 \leq 980$ & rY. I & كلار & $\wedge$ & $1 \leqslant \Psi, V V$ & $1 V \leq 1 \cdot 1$ & $1 Y 11$ & مخمور & $\Lambda$ \\
\hline$\Lambda \varepsilon, Y \Psi$ & $9 r \leq r$. & 1.97 & كفري & 9 & $r v, 9 q$ & 09041 & $107 \mathrm{~V}$ & دوكان & 9 \\
\hline $17 \cdot, 74$ & 174811 & Iror & الطوز & 1. & YIT,IV & VYOT $\leq r$ & $r \varepsilon \cdot \varepsilon$ & السليماتية & 1. \\
\hline$\varepsilon \wedge,+1$ & IFVTYY & ryor & خانقين & 11 & 00,19 & 71019 & 1110 & الابس & 11 \\
\hline$r \vee \wedge, \vee \backslash$ & $r_{1} \leq 0$. & V41 & المقدادية & Ir & $094 \wedge, r)$ & $\varepsilon .0 \wedge \mu \wedge$ & 71 & المحمودية & $1 r$ \\
\hline 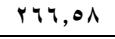 & $r q 0 q \leq r$ & 11.9 & الخالص & ir & $\varepsilon r \Delta \leqslant, Y q$ & $v \cdot 1 . \leq 1$ & 171 & الحلة & ir \\
\hline$\vee V 1, \wedge \varepsilon$ & 9YTAV & $1 Y \wedge 4$ & الاجيل & $1 \varepsilon$ & $\varepsilon q Y, V T$ & rqq०VA & 7.1 & المحاويل & $1 \varepsilon$ \\
\hline 704,11 & $r r v \cdot \Lambda$. & rar & بلد & 10 & $|r \wedge|, \leq \varepsilon$ & rrqrr. & $r O V$ & المسيب & 10 \\
\hline$\varepsilon 0, \wedge \vee$ & Y. $71 V$ & $\varepsilon 0 . \leqslant$ & سامراء & 17 & rrl,00 & $V V \cdot V I r$ & rrqv & كريلاء & 17 \\
\hline$r 7,11$ & IsYoro & $0 \leq \leqslant 0$ & هيت & IV & $7.7, Y V$ & $7 \wedge 79 . r$ & $11 T r$ & النجف & IV \\
\hline$r Y, \Lambda$ & $\leq 91 \vee \ldots$ & V^rq & الرمادي & 11 & rrvi,ov & $r .09 r r$ & $1 \times 9$ & الكوفة & 11 \\
\hline H.Y,Yr & Oหч人ษ & $\varepsilon \vee \wedge$ & الفلوجة & 19 & IY,IV & rrA.r & 1907 & التمر عين & 19 \\
\hline $91, Y 9$ & IIVqY. & $1 \wedge \varepsilon$. & بلدروز & $r$. & rYV, & $I V \leqslant \wedge \diamond V$ & VฯA & تلكيف & r. \\
\hline 104,91 & $1 \leq 540 \mathrm{~V}$ & $9 \leq 7$ & النعمانية & YI & $r \wedge r, I r$ & $\vee \wedge 9 q \ldots$ & rVq. & اربيل & YI \\
\hline $107 \mathrm{~V}, 1 \mathrm{~V}$ & $\varepsilon 99977$ & 119 & الديوانية & YY & $17 r 4,+1$ & Y $1 \wedge 79$. & $1 \% \varepsilon$ & اللهندية & rr \\
\hline PYV,V & $1974 \leqslant 1$ & $7 \ldots$ & الحمزة & $r \mu$ & $r \cdot r, 1$ & ArIA.. q & rVOrA & المجموع & \\
\hline$r \cdot \checkmark, \wedge 1$ & $r \wedge \wedge \vee 1$. & $9 \leq 1$ & السماوه & $r \varepsilon$ & & $r \wedge, 1$ & 17,1 & $\%$ & \\
\hline$Y V \leq \varepsilon, \wedge \uparrow$ & $r 9.900$ & 1.7 & الرميثة & ro & & \multicolumn{3}{|c|}{ اقليم امكانية وصول متوسطة } & \\
\hline$q r \wedge, r q$ & $r q V \leq \cdot r$ & r^o & سوق الثيخ & Y & Or $\varepsilon, r r$ & $r \cdot \Lambda r \cdot r$ & ovV & دهوك & 1 \\
\hline $19 \cdot, \wedge r$ & $\wedge \wedge \leqslant 04$ & 00. & الميمونة & $r V$ & Or,qr & 90109 & 1891 & العمادية & $r$ \\
\hline Y & 141994 & 0.7 & الكبير & rA & - & - & r rar & حلبيجة & $r$ \\
\hline 194,0 & $r \leq 1 \leq 9$. & $1 Y \leqslant \Lambda$ & القرنة & rq & $r v, \diamond v$ & $1 \leq . Y 41$ & TVTr & جمجمال & $\varepsilon$ \\
\hline$r 00,01$ & $\Gamma \leq \Lambda \leq$. & 91 & الفاو & $r \cdot$ & $\varepsilon \vee Y, \Lambda$ & $q r \leqslant V q r$ & 1909 & كركوك & 0 \\
\hline 1,99 & QTYE & $299 Y$ & سلمان & $r$ & $Y Y \leq, O T$ & Y991VI & $\{r \mid$ & ابو غريب & 7 \\
\hline Aqr,1 & $0 \ldots .0 r$ & $\Delta \wedge$. & بعقوية & $r r$ & rotv & OOYIVYI & $10 \leqslant 1$ & بغداد & $\mathrm{V}$ \\
\hline$v \leq r, .9$ & 199191 & r99 & المدينة & $r r$ & 101,199 & $r \cdot \leq 10 \wedge$ & $1 r \leq 0$ & الصويرة & $\Lambda$ \\
\hline \multirow[t]{3}{*}{$1,1, v$} & $\vee \cdot r \wedge . \wedge q$ & 79YYA & المجموع & & $\Lambda \Upsilon, \curlyvee \wedge$ & $1 V 0 \leq 0 \leq$ & YIYY & العزيزية & 9 \\
\hline & $r r, V$ & $\varepsilon r, r$ & $\%$ & & $1 r 0,7 V$ & 101009 & $1 Y \cdot 7$ & عفل & 1. \\
\hline & \multicolumn{3}{|c|}{ اقليم امكانية وصول قليلة جداً } & & $T \leq \varepsilon, V$ & rqqViv & Tr. & الهاشمية & 11 \\
\hline Y I, & $09 \wedge \leq$. & rArq & الدور & 1 & 109,1 & IATYAO & $110 r$ & الخصيب & Ir \\
\hline
\end{tabular}




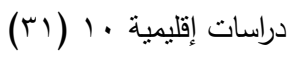

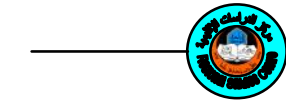

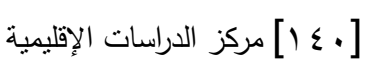

\begin{tabular}{|c|c|c|c|c|c|c|c|c|c|}
\hline نسمة/كمثانية & مدن الأقاليم & مساحة & أمكانية & $ت$ & نسمة/كمثانية & مدن الأقاليم & مساحة & أمكانية & $ت$ \\
\hline$r 11,1 Y$ & Y.9YIV & 991 & تكريت & $r$ & rvo,19 & $\leq Y 0 \leq V 1$ & $111 \leq$ & الزبير & $1 \pi$ \\
\hline $107, .9$ & $1 \wedge 0 \leqslant r$. & $11 \wedge 1$ & بيجي & $r$ & $1 \cdot \wedge r, v 0$ & 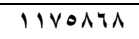 & 1.10 & البصرة & $1 \leq$ \\
\hline $01,7 \leq$ & AVYIQ & 1719 & حليثة & $\varepsilon$ & $V \cdot \varepsilon, 9 Y$ & rrArqE & TrE & المناذرة & 10 \\
\hline$\varepsilon, 7 V$ & एभI & $009 V$ & عنه & 0 & - & $100 Y \leq V$ & ${ }^{-\dot{\varepsilon}}$ & سوران & 17 \\
\hline$\Gamma, \varepsilon \wedge$ & $19 \times 47$ & 0IV4 & راوه & 7 & rqY, 1 & $100 Y \leqslant V$ & OrY & درينديخان & iv \\
\hline Yr,Ys & $10.1 \leq 7$ & $7 \leq 7$. & القائم & $\mathrm{V}$ & $\Lambda \cdot \Lambda, \cdot\urcorner$ & $r Y q \leq \Lambda \Lambda$ & $Y \wedge \varepsilon$ & الثامية & 11 \\
\hline 11,14 & $r q \ldots$ & ro.r & الرطبة & $\Lambda$ & $\varepsilon 77, r$ & $1 \cdot v \leqslant r \leqslant q \leqslant$ & rr.s. & المجموع & \\
\hline $1 \%, 7$ & $r \leq \varepsilon \cdot V$ & $189 \varepsilon$ & بدرة & 9 & & $r q, r$ & $1 \leq, 1$ & $\%$ & \\
\hline$I V \leqslant, \wedge 0$ & $\varepsilon \varepsilon \leqslant \mid Y \wedge$ & ros. & الكوت & 1. & & & & & \\
\hline r & $\varepsilon \varepsilon V \cdot r$ & rI. V & الغزبي & 11 & & & & & \\
\hline$r V \cdot, r V$ & & $1+\leqslant 0$ & الرفاعي & Ir & & & & & \\
\hline I..r,qr & rAOIYr & $\Gamma \wedge \varepsilon$ & الثطرة & ir & & & & & \\
\hline $0 . r, 7 r$ & $T \leqslant \mu \mid r V$ & IrVV & الناصرية & $1 \varepsilon$ & & & & & \\
\hline & 9111. & ro. & صالحة & 10 & & & & & \\
\hline $9 \leqslant, 04$ & V0Y $\leqslant 0$ & $\Lambda \ldots$ & الكحلاء & 17 & & & & & \\
\hline $1 v 1,00$ & $\varepsilon q .9 \wedge r$ & rヘฯ & ميسان & IV & & & & & \\
\hline IVY, VV & $10 V 0 V 0$ & 915 & الحي & 11 & & & & & \\
\hline Y9,70 & $\leq q \leq r$. & 1798 & الخضر & 19 & & & & & \\
\hline \multirow[t]{2}{*}{$\wedge \cdot, \wedge$} & ros 7191 & $\varepsilon r \wedge \wedge$. & المجموع & & & & & & \\
\hline & Ir & $Y Y, \wedge$ & $\%$ & & & & & & \\
\hline 11. & Y৭४ & $17 \leq 717$ & العرلق & & & & & & \\
\hline
\end{tabular}

(") من عمل الباحث بالاعتماد على الـ DBAS لبرنامج r.9. ArcGIS.

ץ-r. إقليم إمكاتية الوصول قليلة: يضم هذا الإقليم نحو بr مدينة تجانست

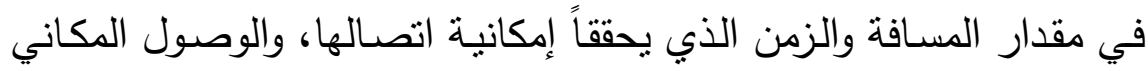

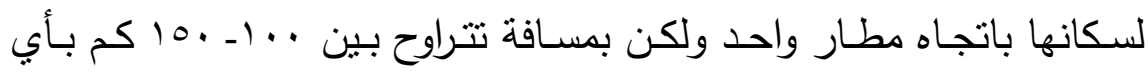

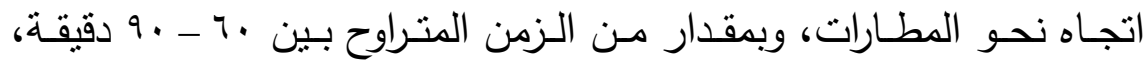
بالرغم مـن أن هذه المدن تتباين بخصائصسه الموضعية لذا حظي الإقليم

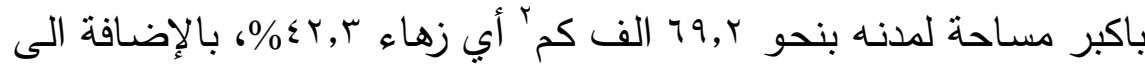

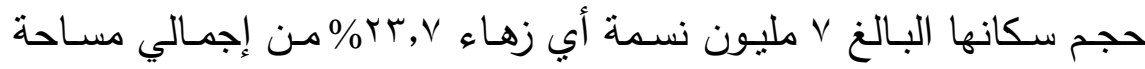

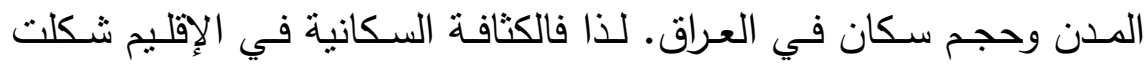

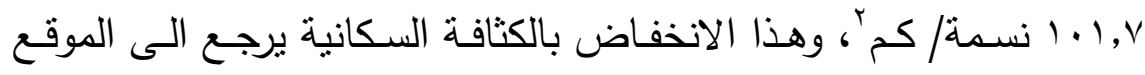




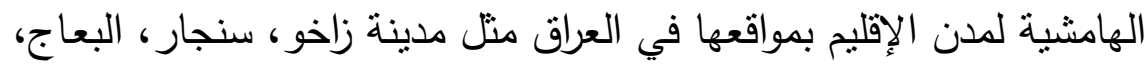

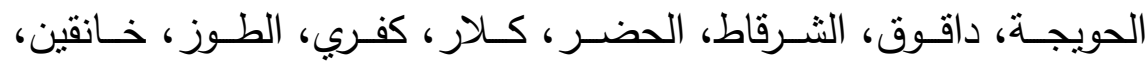

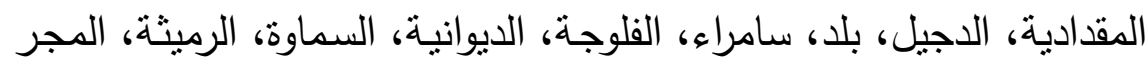

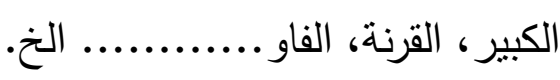

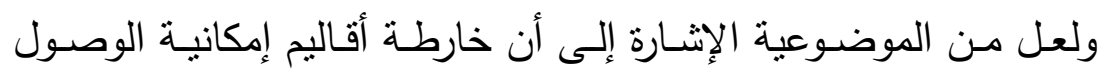

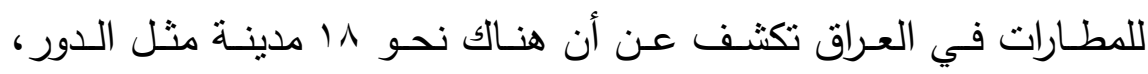

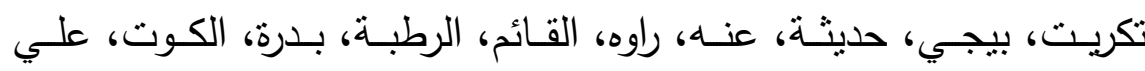

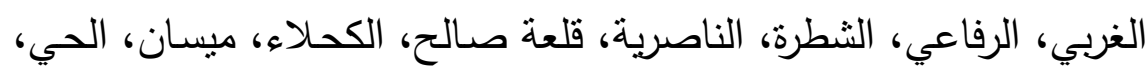

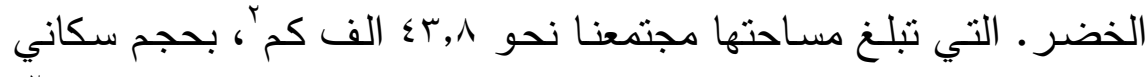

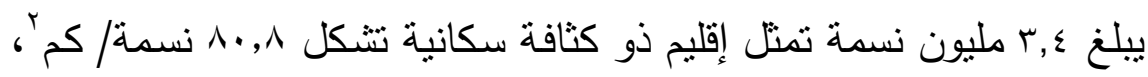

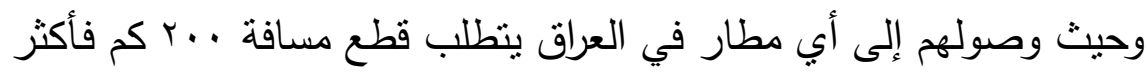

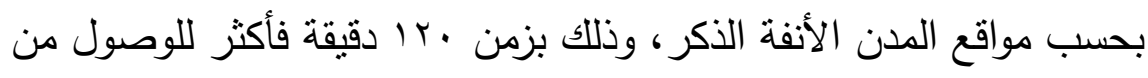

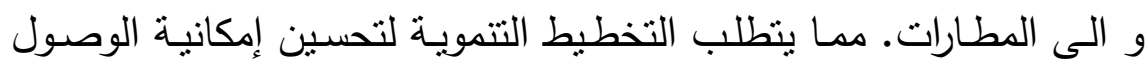
والاستخدام للمطارات من قبل سكان هذه المدن في المستقبل. 
دراسات إقليمية • (1) (ب) (1)

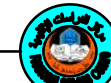

] [ ا [ ] مركز الدراسات الإقليمية

خارطة (r-1 ) أقاليم إمكانية الوصول للمطارات الرئيسة في العرلق

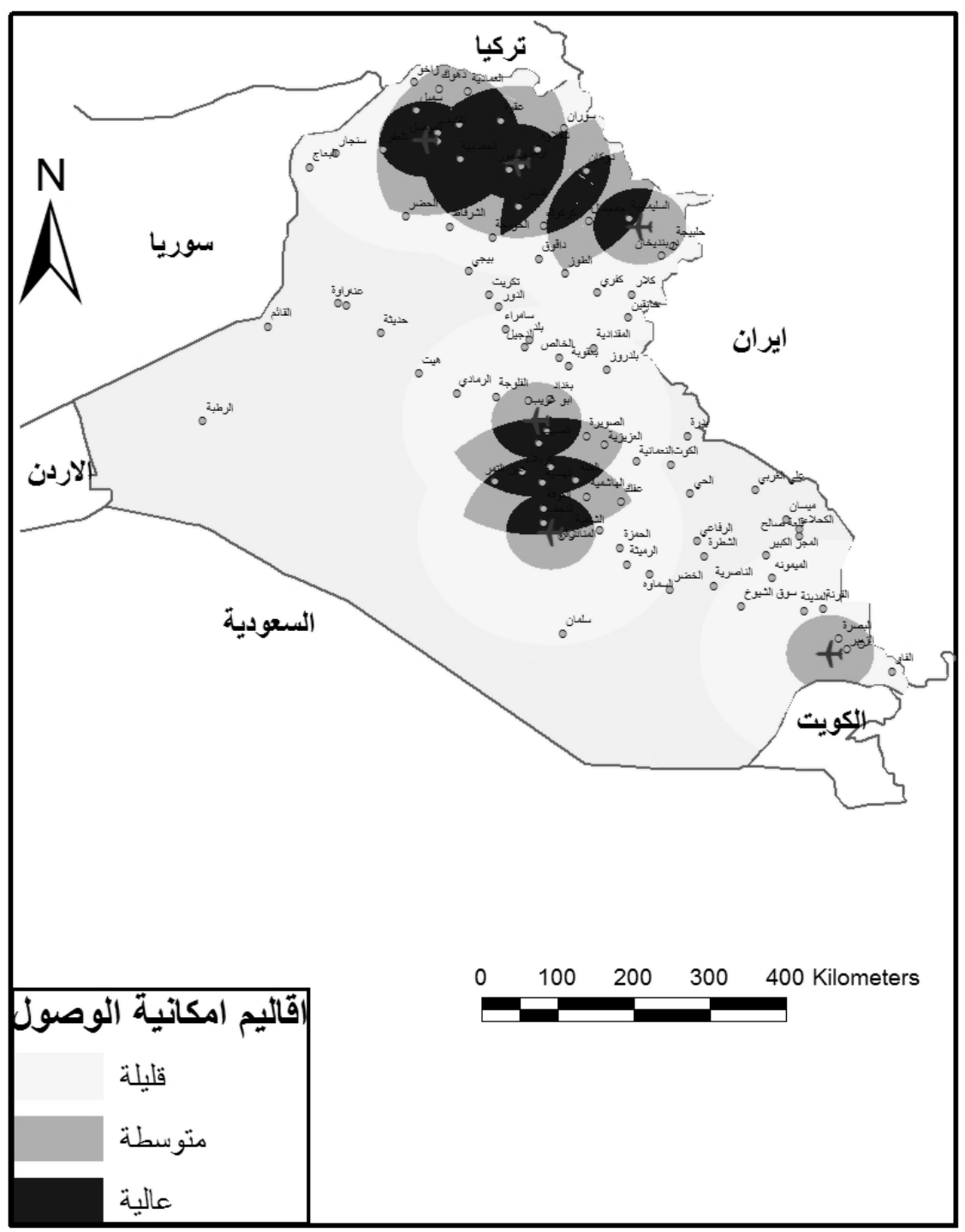


الاستنتاجات والخيارات المطروحة

لخص البحث الى جملة استنتاجات تمثلت بـ:

ا. تعد المطارات إحدى تسـيلات الأنظمـة النقلية كعقد في بيئات توطنها متكاملة بكافة متطلبات العملية النقلية الجوبـة من جهة، والعملية النقلية

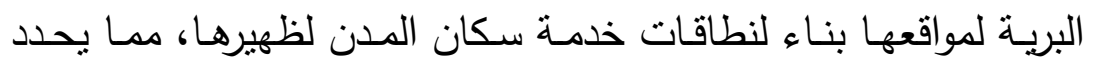

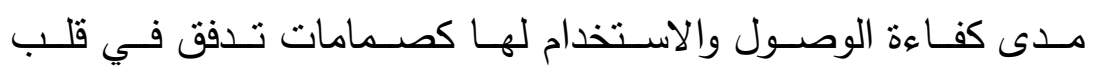
اقتصاديات الدول عبر شراين شبكات النقل البري.

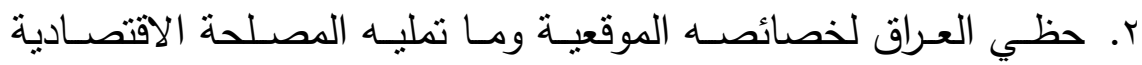
والسياسية والحضـارية في ظل المتغيرات الحديثة من العولمـة والتبـادل

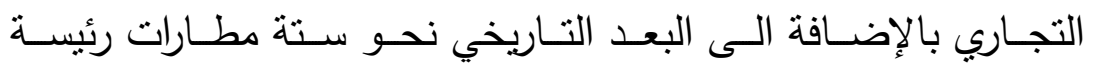
بإمكانياتها التشغيلية التي شهدت توقف نموها وتطورها على مدار أكثر من ربع قرن مما احدث اختلالات هيكلية مكانية في توزيعها وتشغيلها

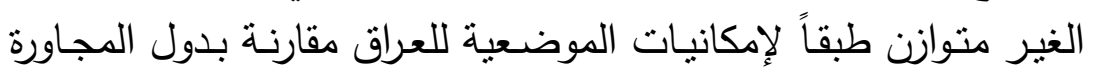
في منطقة الثرق الاوسط. r. تتدرج مطارات العراق طبقاً للمواصفات الهندسية والشكلية في مواضعها

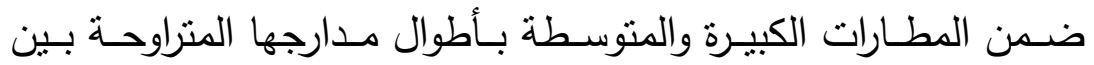

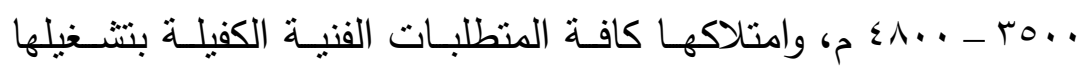

بطاقات استيعابية تتراوح بين r _ _, مليون مسافر كمتوسط سنوي.

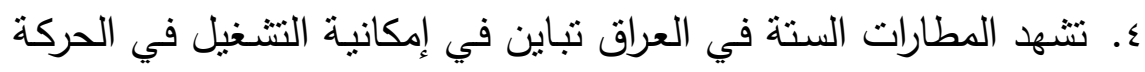

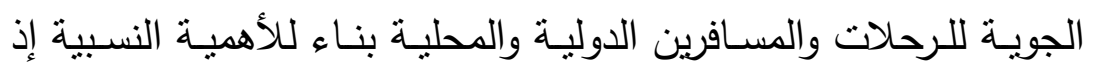
جـاءت مطـارات المنطقة الوسـطى بغداد والنجف بالمقـام الأول بنسبة

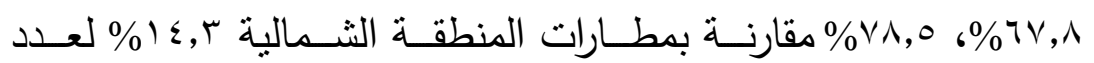
الرحلات الجوية، ₹\% لحجم المسافرين. 
ه. كثنفت الإمكانيـة النطبيقية لـ GIS في تحديد نطاقـات الخدمـة النقلية

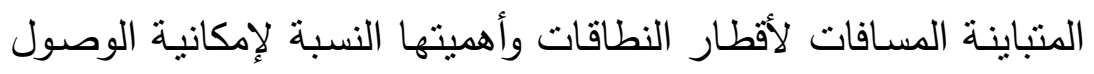

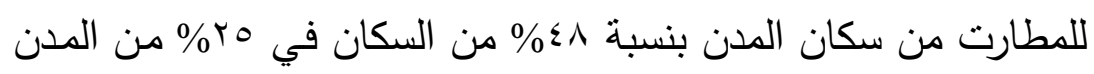

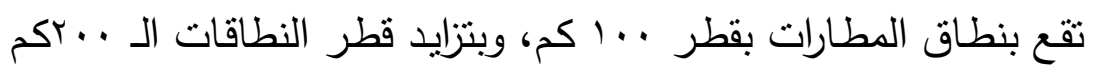

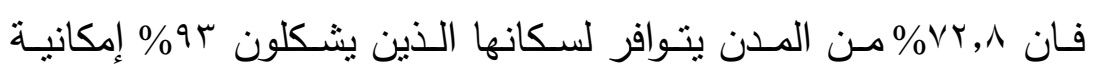

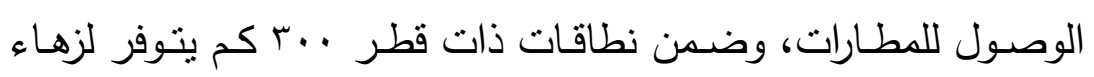

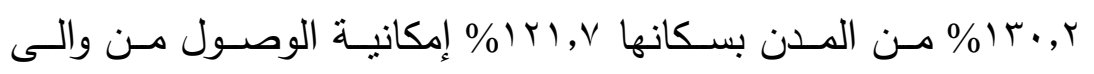
المطارات. وان هناك سكان مدن تتوفر لديهم خيارات أفضلية الاستخدام

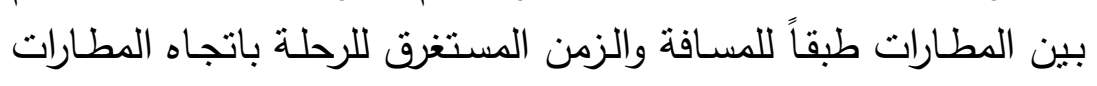
وخاصة في المناطق الوسطى والثنمالية في العراق.

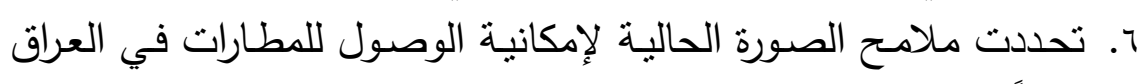

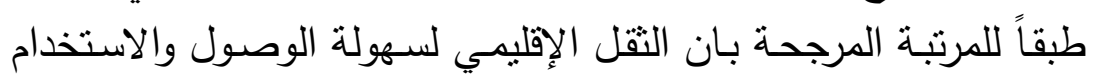
تتحدد بمطار بغداد والنجف لسكان مدن المنطقة الوسطى، لإنه ومطار الربيل

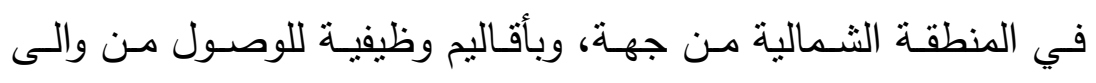

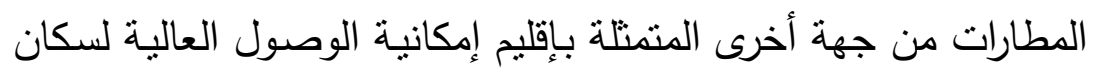

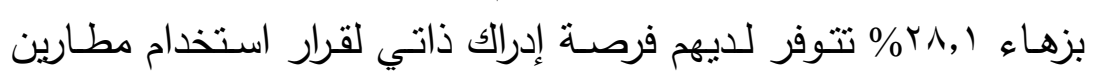

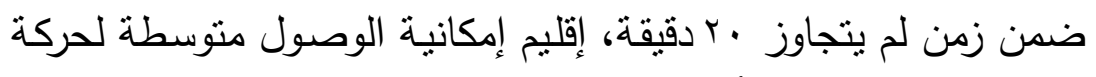

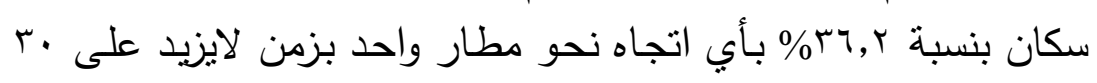

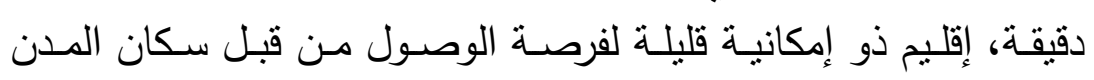

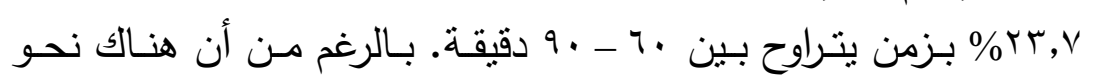

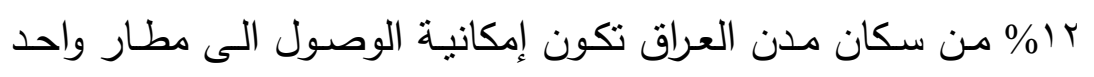

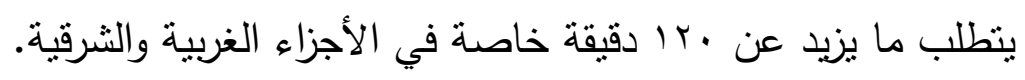

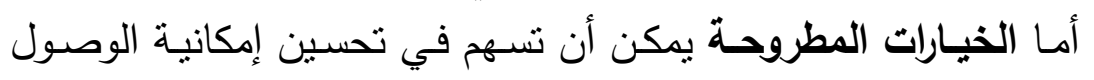
والاستخدام الأفضل للمطارات في العراق تمنلت بـ أن في في 
1. إعادة النظر في هيكلية الإطار التنظيمي للمطارات التي لا تزال مملوكة

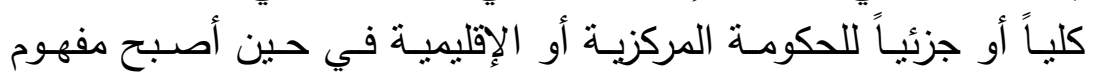

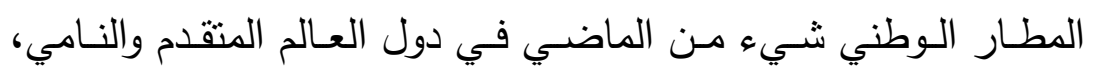

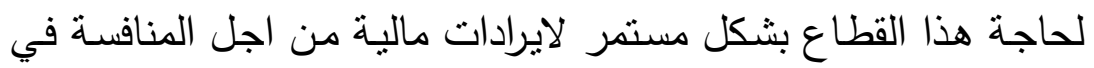
الأسواق العالمبة بظل العولمة. r. الأخذ بنظر الاعتبار زيادة دور التكامل بين نسهيلات العات الأنظمة النقلية

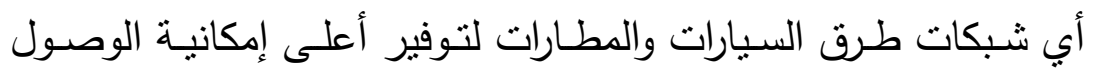

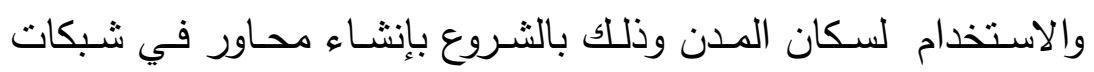
الطرق تكفل أعلى درجات الارتباط لتقليل مقدار الزمن المستغرق للرحلة

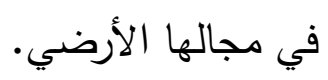

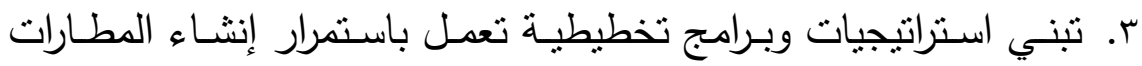

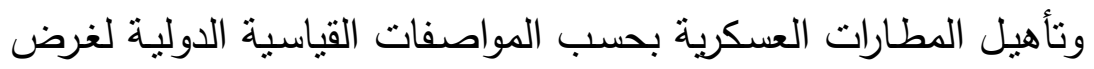

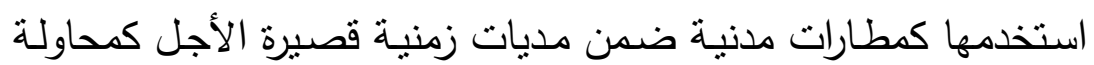

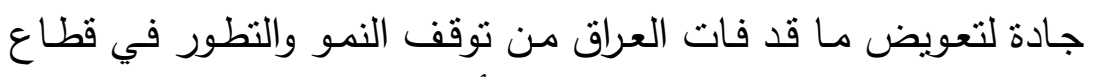

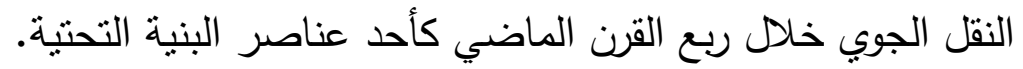

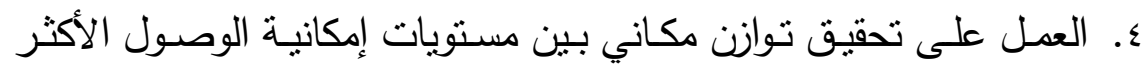

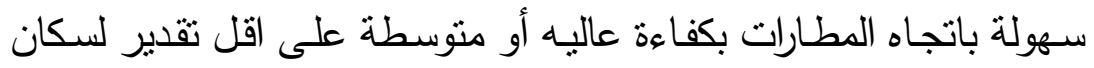

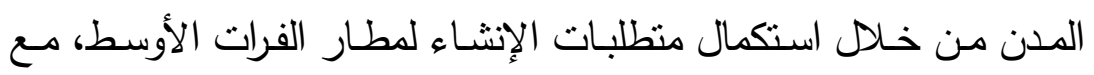

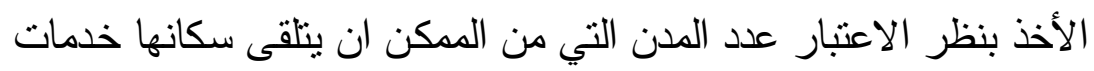

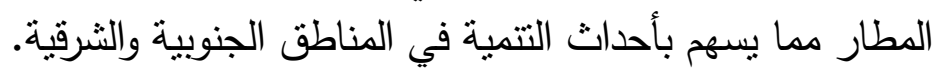

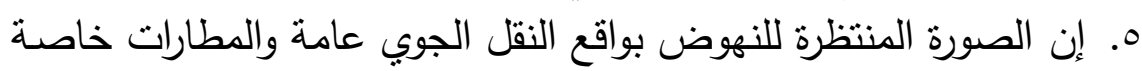

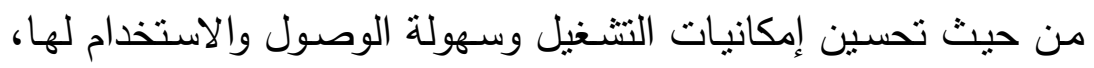

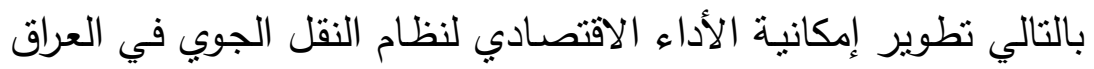

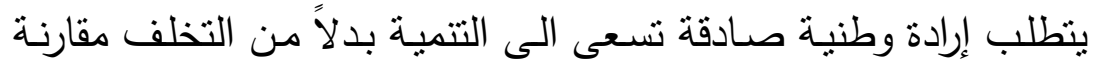
بالمستويات المكانية الإقليمية والدولية. 
دراسات إقليمية • (1) (r)

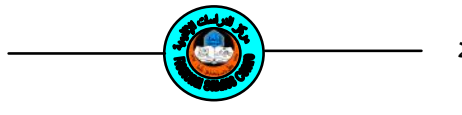

[ ] 1 ] مركز الدراسات الإقليمية

\title{
Possibility of Get Access to Main Airports in Iraq Using GIS
}

\author{
D. Mohanmed Hashion Dhunoon AL hayali \\ Lecture/ Department of Geography/College of Education \\ Mosul University
}

\begin{abstract}
The present research aims at identifying the levels of possibility to get access to the main airports in Iraq using GIS, so at to pinpoint the patterns of spatial interaction between the airports that represent the safeguards of flow into the heart of the economic regions in Iraq, due to the transportation services provided to the city inhabitants according to the distance and time that determine the level of satisfaction with traveling by air and using of airports. The research has concluded with the draw of the regions of possibility of access $b$ multiple hierarchical levels high, medium and low. determine the population's decision to use the airports.. Accordingly, Iraq is lacking the obligatory planning to reinnovate and build airports that can guarantee the achievement of better levels of access possibility from the angle of spatial organization that represents the organic linking between geography and development.
\end{abstract}




\section{الهوامش والمصادر}

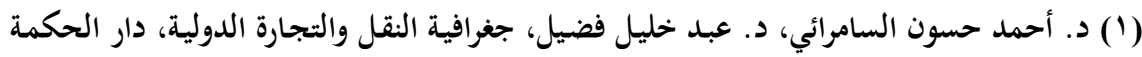

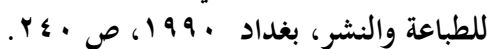

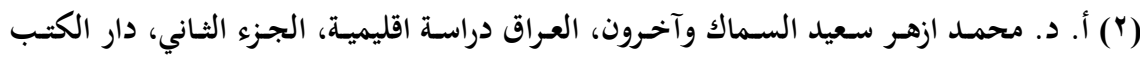

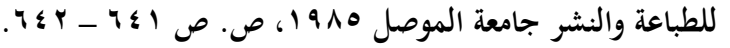

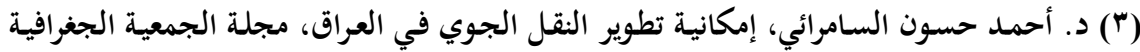

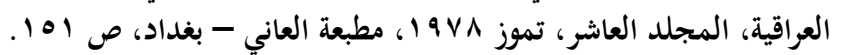

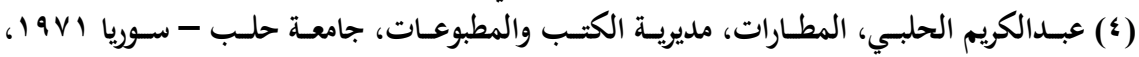

ص ص 1.1

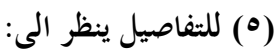

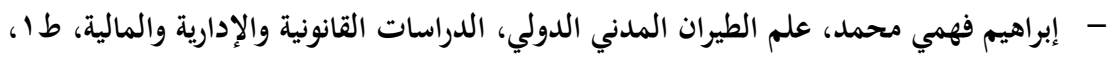

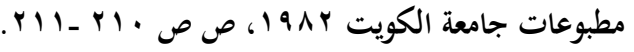

- Jean-Paul Rodrig, The Geography of Transport Systems ,Second Edition,

Claude and Brian Slack, NewYork, $r$. 9 ,p 1 • r

(†) د. روحي لطفي الشريف، مبادئ النقل البري والجوي والبحري والأنابيب، دائرة المكتبة الوطنية

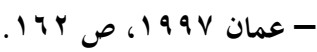

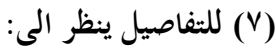

ـ أ. د. محمد ازهـر سعيد السـماك وآخران، جغرافيـة النقل بين المنهجية والنطبيق، طبو، دار

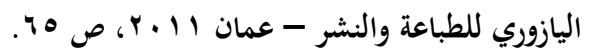

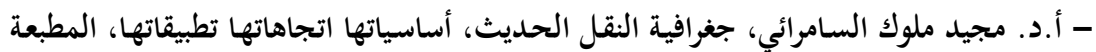

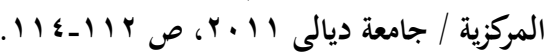

( $\wedge$ Rosario Macario, Airports of the Future: Essentials for A Renewed

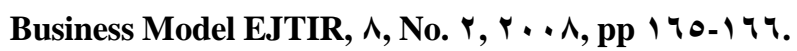

(*) الخدمة النقلية المنطقية، تعتمد هذه الطريقة لتحديد نطاق الخدمة الذي يكون فيها المطار مريحاً

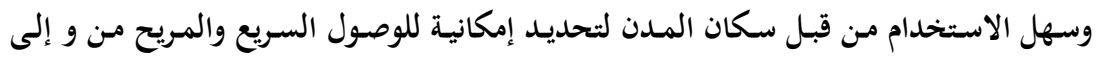

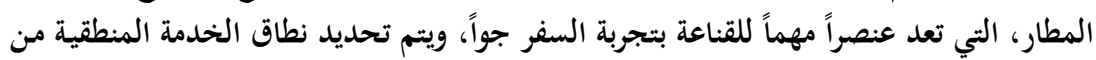

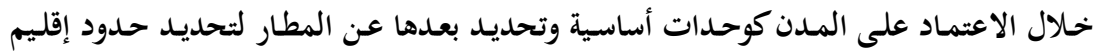

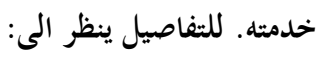

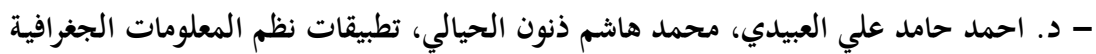

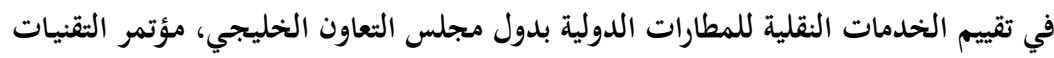


دراسات إقليمية • (1) (ب)

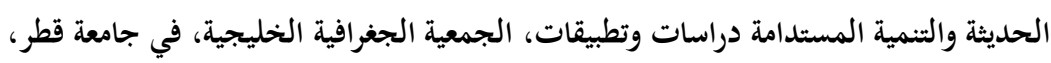

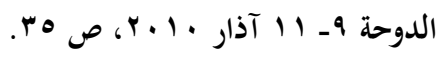

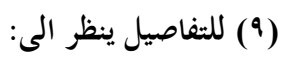

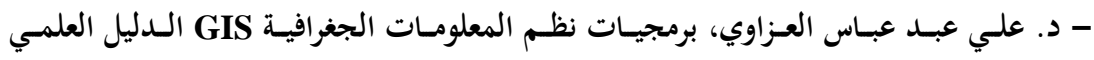

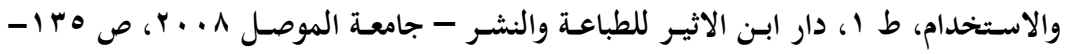
$.1 T V$

- د. قاسم الدويكات، نظم المعلومات الجغرافية النظرية والنطبيق، طا، دار المكتبة الوظنية

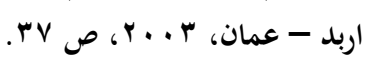

- سميح احمد محمود عودة، أساسيات نظم المعلومات الجغرافية وتطبيقاتها في رؤيه جغرافية،

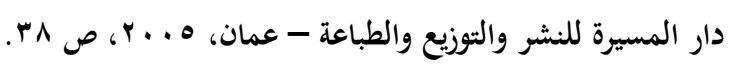

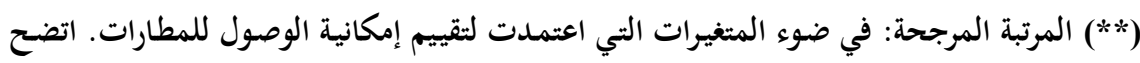

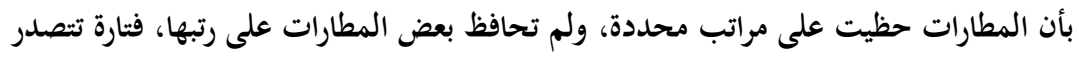

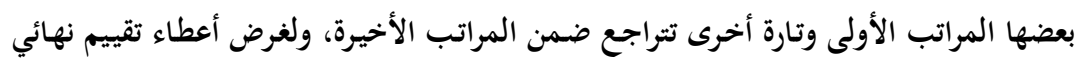

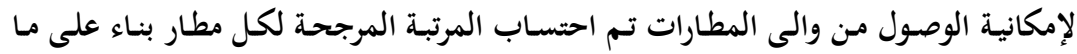

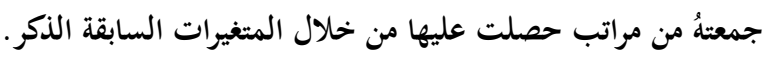

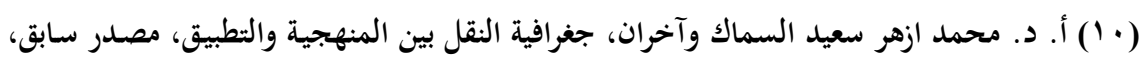

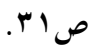

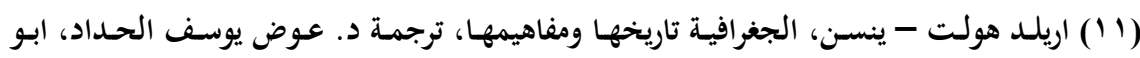

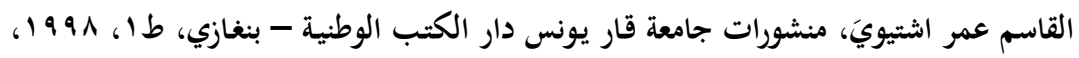

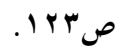

جدول (r-1) الأهمية النسبية وإلمراتب المرجحة لنطاقات إمكانية الوصول للمطارات

طبقاً لسكان المدن في العرلق(") 


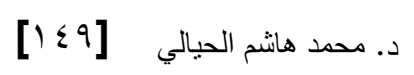

إمكانية الوصول للمطارات ..

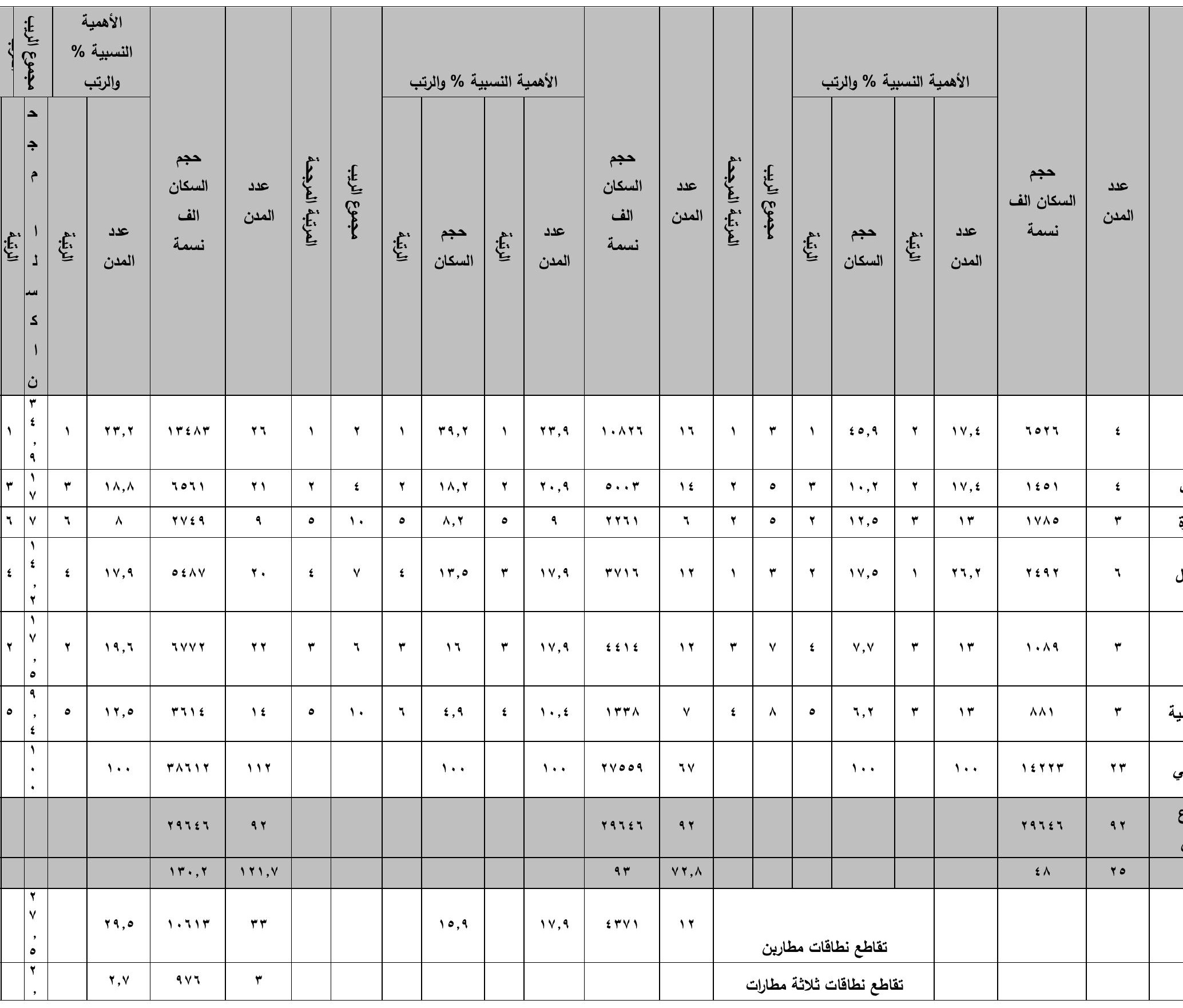


